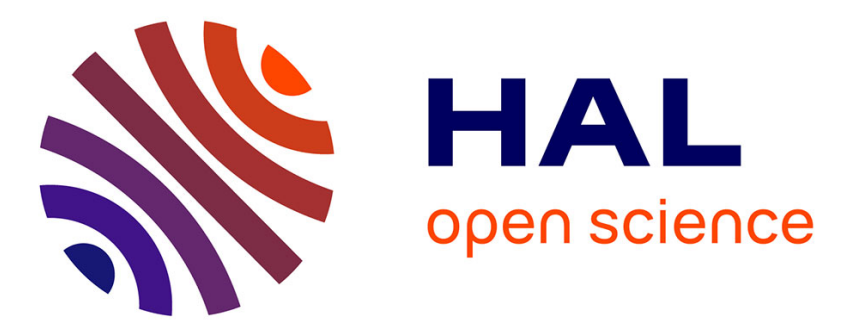

\title{
Solid-State Physics Perspective on Hybrid Perovskite Semiconductors
}

\author{
Jacky Even, Laurent Pedesseau, Claudine Katan, Mikaël Kepenekian, \\ Jean-sébastien Lauret, Daniel Sapori, Emmanuelle Deleporte
}

\section{To cite this version:}

Jacky Even, Laurent Pedesseau, Claudine Katan, Mikaël Kepenekian, Jean-sébastien Lauret, et al.. Solid-State Physics Perspective on Hybrid Perovskite Semiconductors. Journal of Physical Chemistry C, 2015, 119 (19), pp.10161-10177. 10.1021/acs.jpcc.5b00695 . hal-01138487

\section{HAL Id: hal-01138487 \\ https://hal.science/hal-01138487}

Submitted on 25 Nov 2016

HAL is a multi-disciplinary open access archive for the deposit and dissemination of scientific research documents, whether they are published or not. The documents may come from teaching and research institutions in France or abroad, or from public or private research centers.
L'archive ouverte pluridisciplinaire HAL, est destinée au dépôt et à la diffusion de documents scientifiques de niveau recherche, publiés ou non, émanant des établissements d'enseignement et de recherche français ou étrangers, des laboratoires publics ou privés. 
J. Phys. Chem. C, 2015, 119 (19), pp 10161-10177 DOI: 10.1021/acs.jpcc.5b00695

\section{A Solid State Physics Perspective on Hybrid}

\section{Perovskite Semiconductors}

Jacky Even,,${ }^{* \dagger}$ Laurent Pedesseau, ${ }^{\dagger}$ Claudine Katan,,${ }^{*}$ Mikaël Kepenekian, ${ }^{*}$ Jean-Sébastien

Lauret, ${ }^{*}$ Daniel Sapori,,$^{\dagger}$ and Emmanuelle Deleporte ${ }^{¥}$

${ }^{\dagger}$ Fonctions Optiques pour les Technologies de l'Information, FOTON UMR 6082, CNRS, INSA de Rennes, 35708 Rennes, France

* Institut des Sciences Chimiques de Rennes, ISCR UMR 6226, CNRS, Université de Rennes 1, 35042 Rennes, France

${ }^{\gamma}$ Laboratoire Aimé Cotton, Ecole Normale Supérieure de Cachan, CNRS, Université Paris-Sud, Bât, 505 Campus d'Orsay, 91405 Orsay, France

\section{Corresponding Author}

*Email: Jacky.Even@insa-rennes.fr Tel: +33 (0)2 23238295

\section{TOC GRAPHICS}

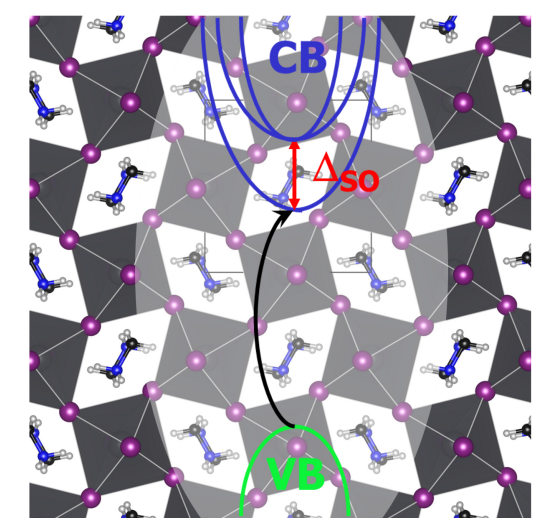

KEYWORDS Photovoltaics, optoelectronics, exciton, Bloch function, band folding, Auger effect 
J.Phys. Chem.C, 2015, 119 (19), pp 10161-10177 DOI: 10.1021/acs.jpcc.5b00695

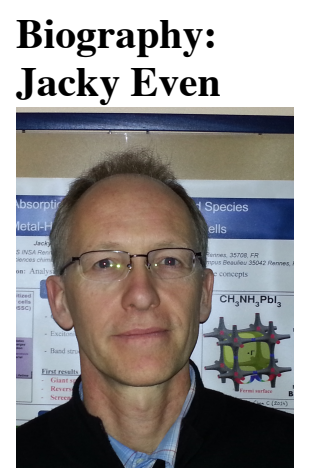

Jacky Even is full Professor at INSA Rennes engineering school since 1999. He received a PhD in Physics from the University of Paris VI in 1992. He was assistant professor at the Physics Department of Rennes University (1992-1999), where he gained broad experience in phase transitions and solid-state chemical reactions in molecular materials, using theoretical and experimental approaches: neutron and X-ray scattering, Raman/FTIR spectroscopy, calorimetry, among others. In 1999, he created FOTON laboratory's simulation team, to address fundamental questions on semiconductors at the atomistic level as well as to perform optoelectronic device simulation. Besides hybrid perovskite materials and colloidal nanoplatelets, his theoretical activity is now dedicated to semiconductor nanostructures, photovoltaic and light emitting (LED, laser, ...) devices for silicon photonics and optical telecommunication.

\section{Laurent Pedesseau}

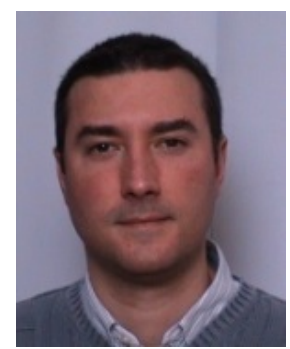

Born March 12, 1975, Laurent Pedesseau obtained his MSc in condensed matter from the University of Montpellier in 2001. In 2004, he received his $\mathrm{PhD}$ in physics from the University of Toulouse for atomistic empirical simulations applied to Civil Engineering materials. In 2013, he was appointed as assistant-professor at FOTON laboratory (INSA Rennes) to work on III-V semiconductor nanostructures for silicon photonics, hybrid-perovskites for photovoltaics and optoelectronic device simulations for optical telecommunication.

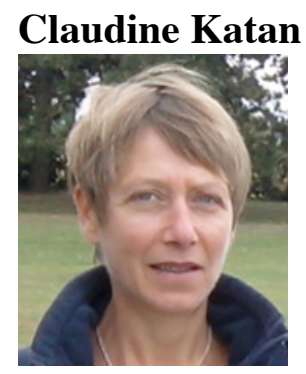

Dr. Claudine Katan, born Hoerner, received a PhD in Physics from the University of Strasbourg in 1992, working with Pr. Albert Villaeys and Dr. Jean-Pascal Lavoine on dephasing effects in four-wave mixing experiments studied using density matrix formalism. She subsequently served 
as lecturer in physics at the University of Rennes before being appointed as a CNRS Research Investigator in the Physics department in 1993. Until 2003, her research interests mainly focused on the properties of molecular charge-transfer crystals and topology of electron densities. She then joined the Chemistry department, interspersed by a two years stay at FOTON-OHM. Her current research at ISCR is devoted to theoretical approaches from modeling to state-of-the-art electronic structure calculations for structural, electronic and linear/non-linear optical properties (e.g. two-photon absorption) of molecular chromophores, but also of hybrid perovskites for light emission and photovoltaic technologies. Her theoretical research is usually conducted in close collaboration with experimentalists.

\section{Mikaël Kepenekian}

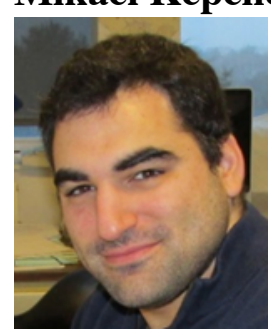

Dr. Mikaël Kepenekian graduated from the ENS de Lyon in Chemistry with a thesis work on molecular magnetism. After a PhD on bistable molecular materials conducted at ENS Lyon and CEA Grenoble under the direction of Dr. Pascale Maldivi and Prof. Vincent Robert, he joined the Centro de Investigación en Nanociencia y Nanotecnología (CIN2) in Bellaterra, Spain working with Prof. Nicolás Lorente on density functional theory applied to electron transport calculations using the non-equilibrium Green's functions formalism. In 2013, he was appointed as a CNRS Researcher at ISCR. His research is devoted to the simulation of semiconductors and interfaces such as molecules supported on surfaces.

\section{Jean-Sébastien Lauret}

After a $\mathrm{PhD}$ on the optical properties of carbon nanotubes and a post doc on boron nitride, he was appointed as assistant professor at ENS Cachan. There, he developed activities on the optical properties of 2D hybrid organic perovskites. He has also an activity on carbon nanostructures. J.S. Lauret is now professor at Ecole Normale Supérieure de Cachan.

\section{Daniel Sapori}

Born on November 28th, 1991, Daniel Sapori graduated from the engineering school CPE Lyon in chemistry and chemical engineering and also obtained an MSc in nanotechnology. Now, he is a PhD student in the simulation group of the FOTON laboratory (INSA Rennes) working on electronic and optical properties of hybrid perovskites under the supervision of Jacky Even.

\section{Emmanuelle Deleporte}

Emmanuelle Deleporte is Professor at Ecole Normale Supérieure de Cachan, head of the Physics Department since 2006. Her research activites are conducted in Laboratoire Aimé Cotton. She is a specialist in optical properties of semiconductors (SCs): semimagnetic SCs, II-VI and III-V $\mathrm{SCs}$, heterostructures such as quantum wells and quantum dots, hybrid perovskites. Her main interests are the study of the excitonic effects, the relaxation dynamics of the carriers, the exciton-phonon interaction and the light-matter interaction, in the framework of opto-electronics: lasers, electroluminescent diodes and photovoltaïc systems. 
J. Phys. Chem. C, 2015, 119 (19), pp 10161-10177 DOI: 10.1021/acs.jpcc.5b00695

\section{COVER ART}
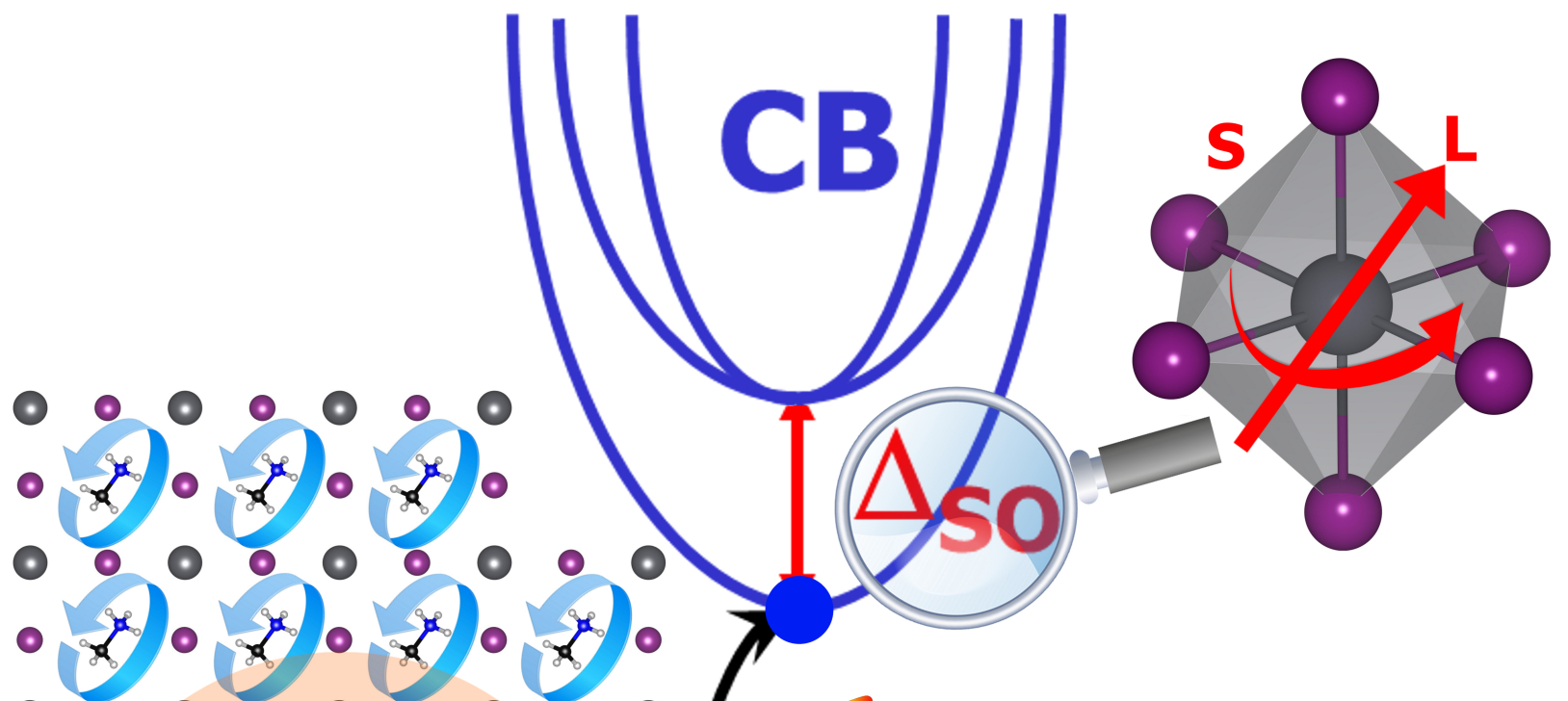

- $\circ \circ \circ 0.0 \%$

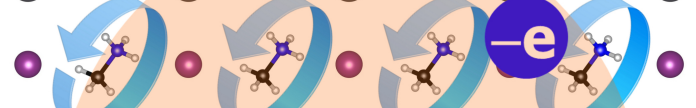

$\circ \circ \circ \circ \circ \circ \%$ - x - x $2 x \cdot x$

- $\odot \circ \circ \% \circ \%$

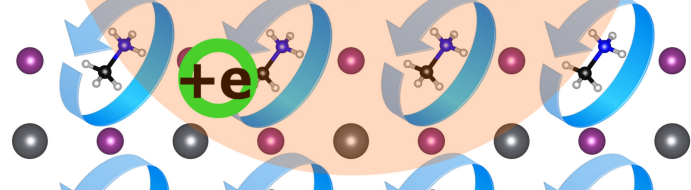

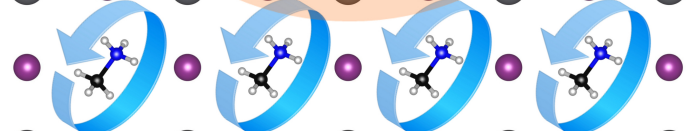

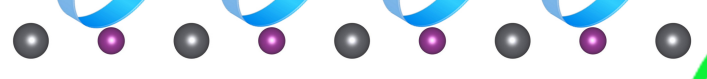
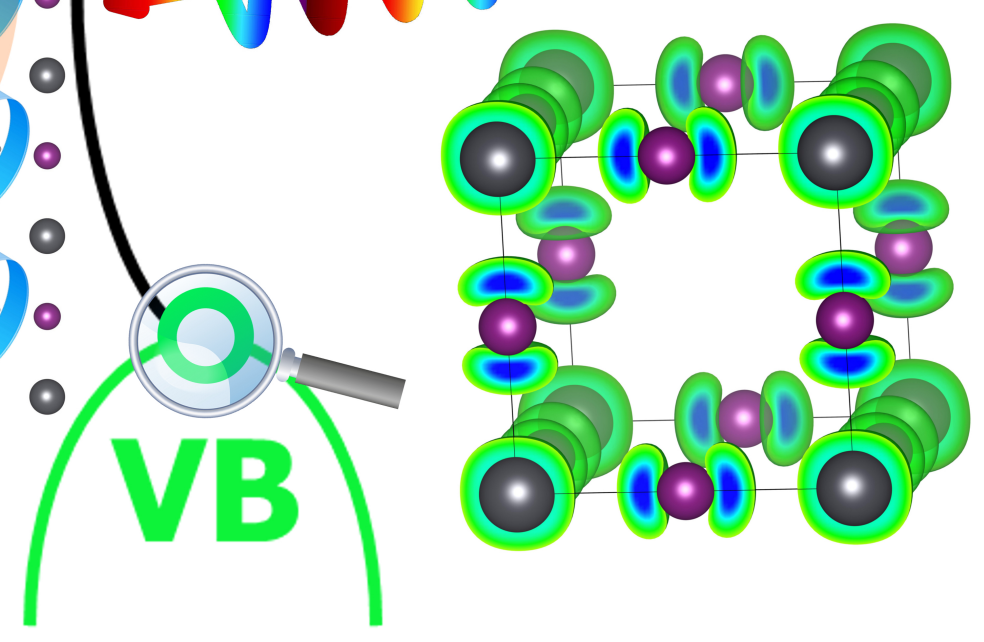
ABSTRACT In this review we examine recent theoretical investigations on 2D and 3D hybrid perovskites (HOP) that combine classical solid-state physics concepts and density functional theory (DFT) simulations as a tool for studying their optoelectronic properties. Such an approach allows one to define a new class of semiconductors, where the pseudocubic high temperature perovskite structure plays a central role. Bloch states and k.p Hamiltonians yield new insight into the influence of lattice distortions, including loss of inversion symmetry, as well as spin-orbit coupling. Electronic band folding and degeneracy, effective masses and optical absorption are analyzed. Concepts of Bloch and envelope functions, as well as confinement potential are discussed in the context of layered HOP and 3D HOP heterostructures. Screening and dielectric confinements are important for room temperature optical properties of 3D and layered HOP, respectively. Non-radiative Auger effects are analyzed for the first time close to the electronic band gap of 3D hybrid perovskites.

\section{INTRODUCTION}

Most metal-halide Hybrid Organic Perovskites (HOP) have the general formulae $\left(\mathrm{R}-\mathrm{NH}_{3}\right)_{\mathrm{n}} \mathrm{MX}_{\mathrm{m}}$, where $\mathrm{R}$ is an organic group, $\mathrm{X}$ a halogen atom $(\mathrm{X}=\mathrm{I}, \mathrm{Br}, \mathrm{Cl})$ and $\mathrm{M}$ a metal atom $(\mathrm{M}=\mathrm{Pb}, \mathrm{Sn}$, $\mathrm{Ge})$. Control of the stoichiometry $(\mathrm{n}, \mathrm{m})$ affords crystal packing of various dimensionalities, ranging from three-dimensional $(3 \mathrm{D}, \mathrm{n}=1$ and $\mathrm{m}=3)$ corner-shared perovskite lattices to $0 \mathrm{D}$ structures with isolated inorganic octahedra. In less than 30 years, the low-cost technologies and the easy synthesis of the layered HOP $(\mathrm{m}>3)$ raised up the interest in the field of optoelectronics and microelectronics. ${ }^{1-15}$ A scientific breakthrough for solar cells was achieved in the last three years with 3D HOP. ${ }^{16-54}$ In both cases, lead-halide based HOP are currently the most investigated, but substitution of the critical metals $(\mathrm{Pb})$ has to be addressed because of environmental issues. 


\section{J. Phys. Chem.C, 2015, 119 (19), pp 10161-10177 DOI: 10.1021/acs.jpcc.5b00695}

Indeed, tin-based layered HOP exhibit hole transport and natural doping, and were shown to be suitable for the demonstration of field effect transistor operation. ${ }^{10-12}$ First results on tin-based solar cells were recently obtained with $3 \mathrm{D}$ HOP..$^{29,41,42}$

The quantum and dielectric confinement expected in the 2D layered HOPs $(n=2, m=4)$ prompted active research to develop optoelectronic devices with enhanced performances. ${ }^{11}$ Since 2009, 3D HOPs $(n=1, m=3)$, with relatively small organic cations, have been suggested as a novel class of low-cost solution-processable materials for high efficiency hybrid photovoltaic cells. Tremendous progress has been made in a short period of time since $2012,{ }^{21-35}$ leading to both meso-superstructured solar cells and solid thin-film planar heterojunctions with record solar-toelectrical power conversion efficiencies. In 2013, NREL recognized the so-called 'Perovskite Cells' as a new and specific technology different from dye-sensitized solar cell (DSSC). ${ }^{36-46}$ Recent theoretical works show that better understanding could benefit from tools and concepts developed both in the fields of organic optoelectronics and conventional semiconductors. ${ }^{55-121}$ Indeed, since the initial use of 3D HOP as the sensitizer in conventional DSSC, technological developments have simultaneously led to a gradual shift of fundamental issues from materials chemistry to solid-state physics. This can be envisioned as a change of paradigm. ${ }^{78}$ Further improvements should make the best profits from both fields. As quoted by H. Snaith in a 2013 review: "Solar cells based on perovskite absorbers promise to break the prevailing paradigm by combining both ultimately low cost and high efficiency". ${ }^{34}$ The efficiency of hybrid perovskites solar cells rose rapidly from $3.8 \%$ in 2009 and $6.5 \%$ in 2011 with DSSC-like technologies to about $10 \%$ in 2012 using new concepts. These record values steeply increased to about $15 \%$ in 2013 thanks to new deposition techniques. ${ }^{22,23,27,28}$ At the end of 2014 , optimized conversion efficiency amounts to $19.3 \%^{39}$ and then $20 \%$ in the last (2014) NREL efficiency chart. ${ }^{122}$ A quick 
insight into the possible applications of hybrid perovskites for solar cells can be gained from a couple of recent review papers. ${ }^{33-38}$ Besides, the feasibility of light emitting diodes or lasers with 3D HOP were recently investigated by several research groups. ${ }^{47-50}$

Clearly, understanding physical properties of operational HOPs and design of novel devices with improved performances may greatly benefit from theoretical work. Prior to 2013, most theoretical studies either focused on layered HOP ${ }^{55,57,61}$ purely inorganic $3 \mathrm{D}$ perovskites ${ }^{56,60,62-65}$ and $3 \mathrm{D} \mathrm{HOP},{ }^{55,56,58,59}$ but, in the latter case, missing inherent physical properties such as effect of spin-orbit coupling. In 2013, ${ }^{66-72}$ a few papers have appeared on 3D HOP in relation with the breakthrough in the field of photovoltaics, followed by a large number of papers in 2014: a nearexhaustive list is given in the reference section. ${ }^{73-121}$ Currently, most of the theoretical work relies on the use of Density Functional Theory (DFT) based simulations. They have proved their effectiveness to analyze qualitatively band gaps, effective masses or optical absorption of 2D and 3D materials. It is however difficult to make theoretical predictions or relevant comparisons with physical parameters derived from experiments, especially for structures suited from a device perspective such as HOP heterostructures. In the case of conventional semiconductors materials and heterostructures (e.g. silicon and III-V semiconductors), knowledge often profit most from semi-empirical approaches based on basic solid-state physics concepts and symmetry considerations. ${ }^{61,62,66,74,75,123}$ In such a case, DFT including many-body corrections affords a tool to assess the validity of the semi-empirical approach. However, comparison is limited to particular situations (e.g. small heterostructures) that remain computationally feasible.

This paper aims to review our recent work on HOP that is essentially based on concepts and tools already well deployed in the fields of optoelectronics and conventional semiconductors. But, from the introduction we would like to emphasis major contributions from several other 


\section{J. Phys. Chem.C, 2015, 119 (19), pp 10161-10177 DOI: 10.1021/acs.jpcc.5b00695}

research groups, who were very active from the start in $2013,{ }^{66-70}$ and in early $2014 .{ }^{94-100}$ Close attention will be paid on solid-state physics concepts in the context of HOP. The validity and limitations of mainstream approaches developed for conventional semiconductors will be discussed. Properties that make HOP a new and distinct class of semiconductors will also be emphasized.

The paper is organized as follows. First and foremost, to ensure easier understanding of underlying concepts discussed in the first two sections, effect of spin orbit coupling (SOC) will be temporary left aside. But readers must keep in mind that SOC is essential to capture the main physics in this class of hybrid materials. In Section 2 we introduce the pseudocubic phase as a reference for the investigation of 3D HOP, introduce the corresponding k.p Hamiltonian and list the major differences between conventional and HOP semiconductors. Section 3 is devoted to clarify and distinguish the impact of Brillouin Zone (BZ) folding and lattice strain. Next, importance of SOC will be considered in Section 4 and discussed both for 3D and 2D HOP. In these first four sections, particular attention will be paid to symmetry and how these effects can be accounted for within the k.p method. Section 5 summarizes available information on possible loss of inversion symmetry in crystal structures, and addresses its interplay with SOC that suggests potential applications in spintronics. Sections 6 and 7 deal with quantum confinement and band alignment in layered and 3D HOP, respectively. The nature of photoexcited species (excitons versus free carriers) is analyzed in Section 8 with a special focus on dielectric screening and confinement. Section 9 presents a discussion on the importance of Auger effects, including comparison with III-V semiconductors. Finally, main conclusions are drawn in Section 10. 


\section{THE PSEUDOCUBIC PEROVSKITE STRUCTURE AS A REFERENCE FOR 3D HOP}

Bulk structures of well-known conventional semiconductors adopt either diamond cubic (Fd3m, space group no 227) and zinc-blende (F43m, no 216) ( $\mathrm{Si}, \mathrm{Ge}, \mathrm{C}, \mathrm{GaAs}, \mathrm{InP}, \mathrm{CdSe} . .$.$) unit cells,$ or hexagonal graphite $\left(\mathrm{P} 6_{3} / \mathrm{mmc}\right.$, no 194) and würtzite $\left(\mathrm{P} 6_{3} \mathrm{mc}\right.$, no 186$)(\mathrm{C}, \mathrm{GaN}, \mathrm{ZnO}, \mathrm{CdSe}$, ZnS...) lattices. For zinc-blende and würtzite structures, many of the structural properties are similar to that of diamond and graphite, but loss of inversion symmetry has a subtle impact on the optoelectronic and piezoelectric properties of the crystal.

Let's start with GaAs, which is a reference among conventional cubic semiconductors for optoelectronic applications that exhibits both good optical and transport properties. As stated in the introduction we remind the reader that, for simplicity, in this and the next sections SOC will be disregarded. The density of states (DOS) of cubic GaAs computed within the GGA (Generalized Gradient Approximation) with the SIESTA code is reported in Figure 1a. It shows that both valence (VB) and conduction bands (CB) are associated to hybridized atomic $s$ - and $p$ orbitals of $\mathrm{Ga}$ and As atoms. In order to take advantage of translational symmetry, it is useful to describe the energy eigenfunctions in a bulk crystal as Bloch waves:

$$
\psi_{n, \vec{k}}(\vec{r})=e^{i \vec{k} \cdot \vec{r}} u_{n, \vec{k}}(\vec{r})
$$

where $n$ is the band index, $\boldsymbol{r}$ the position vector, $\boldsymbol{k}$ the wavevector inside the BZ and $u_{n, \boldsymbol{k}}(\boldsymbol{r})$ the periodic part of the eigenfunction. The corresponding energy dispersion curves are represented within the BZ (Figure 1b). A plane wave representation of the Bloch waves would be possible, but Wannier functions based on local atomic orbitals are a good alternative to provide an intuitive avenue of chemical bonding in solids starting from DFT or tight binding results. Triply degenerated electronic states form the valence band maximum (VBM) at the center of the BZ, $\Gamma$ (Figure 1b). The non-degenerate conduction band minimum (CBM) of GaAs also shows up at $\Gamma$ 
and leads to a direct electronic band gap that, at room temperature, is almost the same as that of $\mathrm{CH}_{3} \mathrm{NH}_{3} \mathrm{PbI}_{3}(1.5 \mathrm{eV}),{ }^{33}$ the prototype 3D HOP for solar cells.
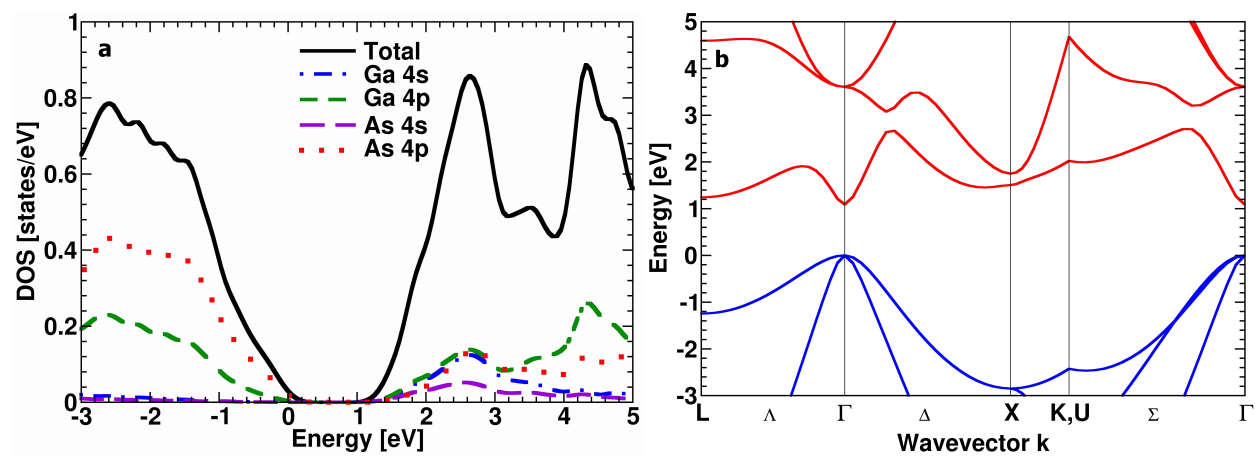

Figure 1. (a) Density of states (DOS) and (b) electronic band dispersion diagram of GaAs in the zinc-blende structure. The energy at the top of the valence band (VB) at $\Gamma$ point is set to $0 \mathrm{eV}$. The DOS close to the band gap is mostly associated to hybridized $\mathrm{s}$ and $\mathrm{p}$ states of the $\mathrm{Ga}$ and As atoms. The conduction bands (CB) and VB are represented respectively as red and blue lines in the band dispersion diagram (b). The computation is performed within the GGA with the SIESTA code. Spin-orbit coupling (SOC) is not considered.

However the situation is more complicated in 3D HOP than in semiconductors like GaAs, due to orientational disorder of the organic cation. Electronic properties of the cubic phase of the prototype $\mathrm{HOP} \mathrm{CH}_{3} \mathrm{NH}_{3} \mathrm{PbI}_{3}$ are best captured taking its all-inorganic analog, $\mathrm{Cs}_{3} \mathrm{PbI}_{3}$. In fact, many effects, such as strain, phase transitions, relativistic effects, local distortions due to the organic cations, loss of inversion symmetry, etc, can be considered as perturbations to a certain extent (vide infra). Figure $2 \mathrm{a}$ represents a real space $3 \mathrm{D}$ view of the $\mathrm{Pm} 3 \mathrm{~m}$ reference cubic crystal structure of metal-halide perovskites of general formulae $\mathrm{AMX}_{3}$ where $\mathrm{A}=\mathrm{Cs}, \mathrm{CH}_{3} \mathrm{NH}_{3}{ }^{+}$, $\mathrm{M}=\mathrm{Pb}, \mathrm{Sn}$ and $\mathrm{X}=\mathrm{I}, \mathrm{Br}, \mathrm{Cl}$. The reciprocal space $3 \mathrm{D}$ view (Figure $2 \mathrm{~b}$ ) shows the first $\mathrm{BZ}$ of the Pm3m space group, with some points of high symmetry. The electronic band structure of the cubic ( $\mathrm{Pm} 3 \mathrm{~m}$, no 221) phase of $\mathrm{CH}_{3} \mathrm{NH}_{3} \mathrm{PbI}_{3}$ is shown on Figure 2c. An upward energy shift of $0.3 \mathrm{eV}$ has been applied to match the experimental bandgap value at $\mathrm{R}$. The $\mathrm{CH}_{3} \mathrm{NH}_{3}{ }^{+}$cation is located at the center of the cube with an averaged position. It has been replaced by a $\mathrm{Cs}^{+}$cation 
for the computation of the band structure. The electronic structure of the reference cubic phase of $\mathrm{CH}_{3} \mathrm{NH}_{3} \mathrm{PbI}_{3}$ reveals two main differences when compared with GaAs (Figure 1): ${ }^{66}$

- Direct band gap located at the high symmetry point $R$ instead of $\Gamma$;

- Inverted band structure: the triply degenerate electronic state is located at CBM instead of VBM.

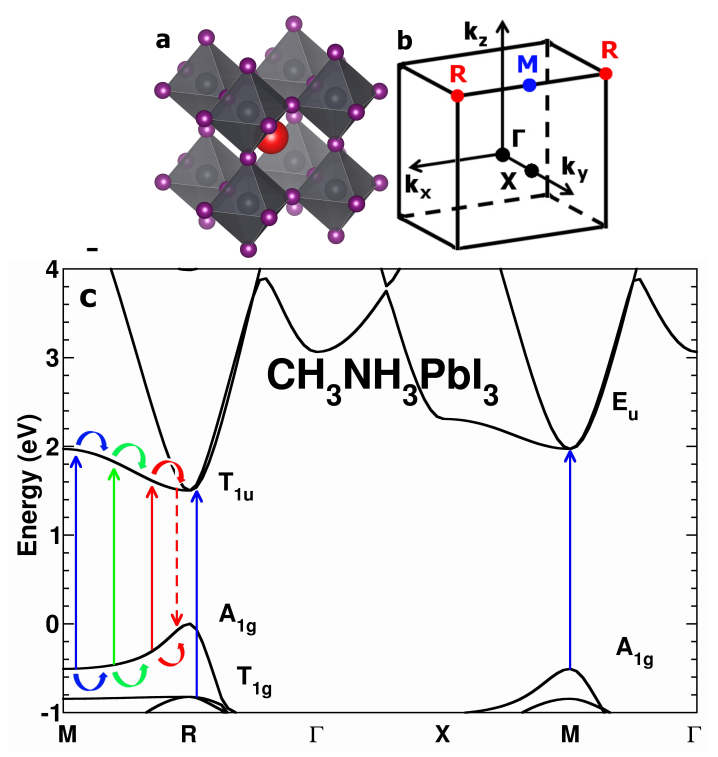

Figure 2. (a) Real space 3D view of the Pm3m reference cubic crystal structure of metalhalide hybrid perovskites of general formulae $\mathrm{AMX}_{3}$ where $\mathrm{A}=\mathrm{Cs}, \mathrm{CH}_{3} \mathrm{NH}_{3}{ }^{+}, \mathrm{M}=\mathrm{Pb}$, Sn and $\mathrm{X}=\mathrm{I}, \mathrm{Br}, \mathrm{Cl}$. In hybrid perovskites, the $\mathrm{CH}_{3} \mathrm{NH}_{3}{ }^{+}$cation is located at the center of the cube with an averaged position sketched by the red ball. (b) Reciprocal space 3D view showing the first BZ of the Pm3m space group. Points of high symmetry in the cubic BZ are indicated by conventional letters: $\Gamma$ denotes the origin of the BZ; $X$ is the center of a square face at the $\mathrm{BZ}$ boundary, $\mathrm{M}$ is a center of a cube edge; and $\mathrm{R}$ are vertices of the cube. (c) Electronic band structure for the high temperature cubic $\mathrm{Pm} 3 \mathrm{~m}$ phase of $\mathrm{CH}_{3} \mathrm{NH}_{3} \mathrm{PbI}_{3}$ without $\mathrm{SOC}$ at the LDA (Local Density Approximation) level of theory. An upward energy shift of $0.3 \mathrm{eV}$ has been applied to match the experimental bandgap value at R. Irreducible representations obtained from a Pm3m simple group analysis, are given at R and M points for the electronic states close to the band gap. Vertical arrows show various possible optical transitions close to the band gap energy. Optical transitions along the line between the $\mathrm{M}$ and $\mathrm{R}$ points generate carriers that easily relax toward the $\mathrm{R}$ point. Reprinted with permission from ref 75 . Copyright 2014 American Chemical Society.

The dispersion curves close to the critical point $\mathrm{R}$ of the $\mathrm{BZ}$ can be analysed within a multiband effective mass model (k.p method) ${ }^{74}$ as a function of the $\mathbf{k}$-vector, which represents the 


\section{J.Phys. Chem.C, 2015, 119 (19), pp 10161-10177 DOI: 10.1021/acs.jpcc.5b00695}

difference with the wavevector at $\mathrm{R}$ point $\mathbf{k}_{\mathrm{R}}$. The corresponding $\mathbf{k}$-dependent Hamiltonian for the triply degenerate CBM deduced from a symmetry analysis reads: ${ }^{66,74,75}$

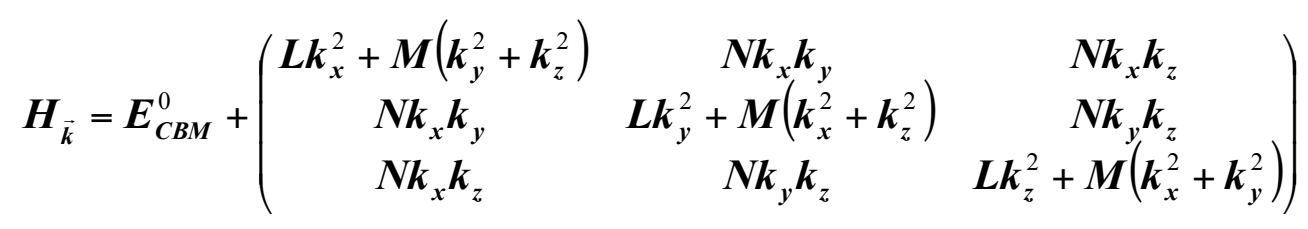

for the simple group $\mathrm{T}_{1 \mathrm{u}}$ vectorial irreducible representation (IR) of the CBM at R. $L, M$ and $N$ are parameters that can be extracted either from experiment or DFT calculations. The basis Bloch functions at $\mathrm{R}$ for this IR are associated to $p_{x}, p_{y}, p_{z}$ atomic orbitals of $\mathrm{Pb}$ and can thus be labeled $|\boldsymbol{X}\rangle,|\boldsymbol{Y}\rangle,|\boldsymbol{Z}\rangle$ by analogy to the Bloch functions at VBM in diamond and zinc-blende lattices. In the Pm3m cubic structure at R, VBM corresponds to the totally symmetric $\mathrm{A}_{1 \mathrm{~g}} \mathrm{IR}$ of the simple group. The basis Bloch function for this IR is associated to $p_{x}, p_{y}, p_{z}$ orbitals of iodine and the $s$ orbital of lead and can thus be labeled $|S\rangle$ by analogy to the Bloch functions at the CBM in zinc-blende lattices with direct band gap. ${ }^{123}$

The symmetry analysis of the electronic states at $\mathrm{R}$ and $\mathrm{M}$ points allows identifying the optically allowed transitions. The strength of the optical transitions can be evaluated from energy parameters for the optical matrix elements, obtained for each pair of $[\mathrm{CB}, \mathrm{VB}]$ states from the expression: $\frac{2}{m_{e}}\left|\left\langle\psi_{C B}|-i \hbar \nabla| \psi_{V B}\right\rangle\right|^{2}$. In the case of the fundamental optical transition they can be related to the Kane energy, which is commonly used in semiconductor physics. ${ }^{123}$ For $\mathrm{CH}_{3} \mathrm{NH}_{3} \mathrm{PbI}_{3}$, they amount to 40 and $120 \mathrm{eV}$ for the fundamental transitions at $\mathrm{R}$ and $\mathrm{M}$, respectively, ${ }^{75}$ but next sections will show that strength of optical absorption crucially depends on other effects, in particular SOC that modifies both band degeneracies and effective masses.

\section{BRILLOUIN ZONE FOLDING FROM THE PSEUDO-CUBIC PHASE IN 3D HOP EVIDENCING EFFECT OF LATTICE STRAIN}




\section{J. Phys. Chem.C, 2015, 119 (19), pp 10161-10177 DOI: 10.1021/acs.jpcc.5b00695}

At high temperature, experimental crystal structures of HOP do not reveal strictly ordered and symmetric phases as a consequence of molecular symmetry of the organic cations that do not fit the site symmetry of the lattice. For 3D HOP, the reference high temperature phase is the cubic phase of $\mathrm{CsPbI}_{3}(\mathrm{Z}=1)$. In fact, for $\mathrm{CH}_{3} \mathrm{NH}_{3} \mathrm{PbX}_{3}$ a similar pseudo-cubic Pm3m phase is observed by diffraction measurements at high temperature, but the positions of all the atoms in the organic molecules are dynamically averaged and occupy the same special Wickoff position at the center of the cubic cell. A first ad-hoc attempt is to completely locate the organic cation within the cubic cell. However, this procedure leads to an artificial reduction of the space group symmetry and corresponds to strong long range dipole-dipole interactions in the lattice, which are not expected to play a role in the static limit. Indeed, the high symmetry of the Pm $3 \mathrm{~m}$ phase is related to a dynamical disorder. A more practical way to make a rigorous theoretical description including all the atoms in an ordered lattice, is to consider the low temperature orthorhombic phases (Pnma, no 62) of $\mathrm{CH}_{3} \mathrm{NH}_{3} \mathrm{PbX}_{3}$ 3D HOP compounds ( $\mathrm{Z}=4$ for $\mathrm{X}=\mathrm{I}$ or $\mathrm{Br}$ and $\mathrm{Z}=8$ for $\mathrm{X}=\mathrm{Cl}$ ). The electronic band gap remains direct but shows up at $\Gamma$ and the number of bands is multiplied by a factor of 4 or 8 with respect to the cubic case. At a first sight, the electronic band structure of the Pnma phase of $\mathrm{CH}_{3} \mathrm{NH}_{3} \mathrm{PbI}_{3}$ (Figure 3a) appears very different from that of the reference cubic phase (Figure 3c). In order to properly understand the connection between the two diagrams, it is necessary to treat both phases on an equal footing. When replacing the organic cations by cesium atoms located at nitrogen positions, the electronic band diagram close to the band gap of HOP remains unchanged.$^{61,66,73}$ This remarkable property is due to the fact that the CBM and VBM electronic states are mostly associated to atomic orbitals of the inorganic octahedra and that the $\mathrm{Cs}^{+}$cations correctly mimic the ionic interactions. This computational trick cannot be used to predict the structural properties of $\mathrm{CH}_{3} \mathrm{NH}_{3} \mathrm{PbX}_{3}$, which depend on other 
interactions not accounted for by this substitution. Nevertheless, the electronic band diagram of the pseudo-cubic $\mathrm{Pm} 3 \mathrm{~m}$ phase of $\mathrm{CH}_{3} \mathrm{NH}_{3} \mathrm{PbX}_{3}$ can be conveniently studied by putting a cesium atom at the center of the cell (average position of the $\mathrm{N}$ atom in the Pm3m lattice) and using the experimental

lattice

constants.

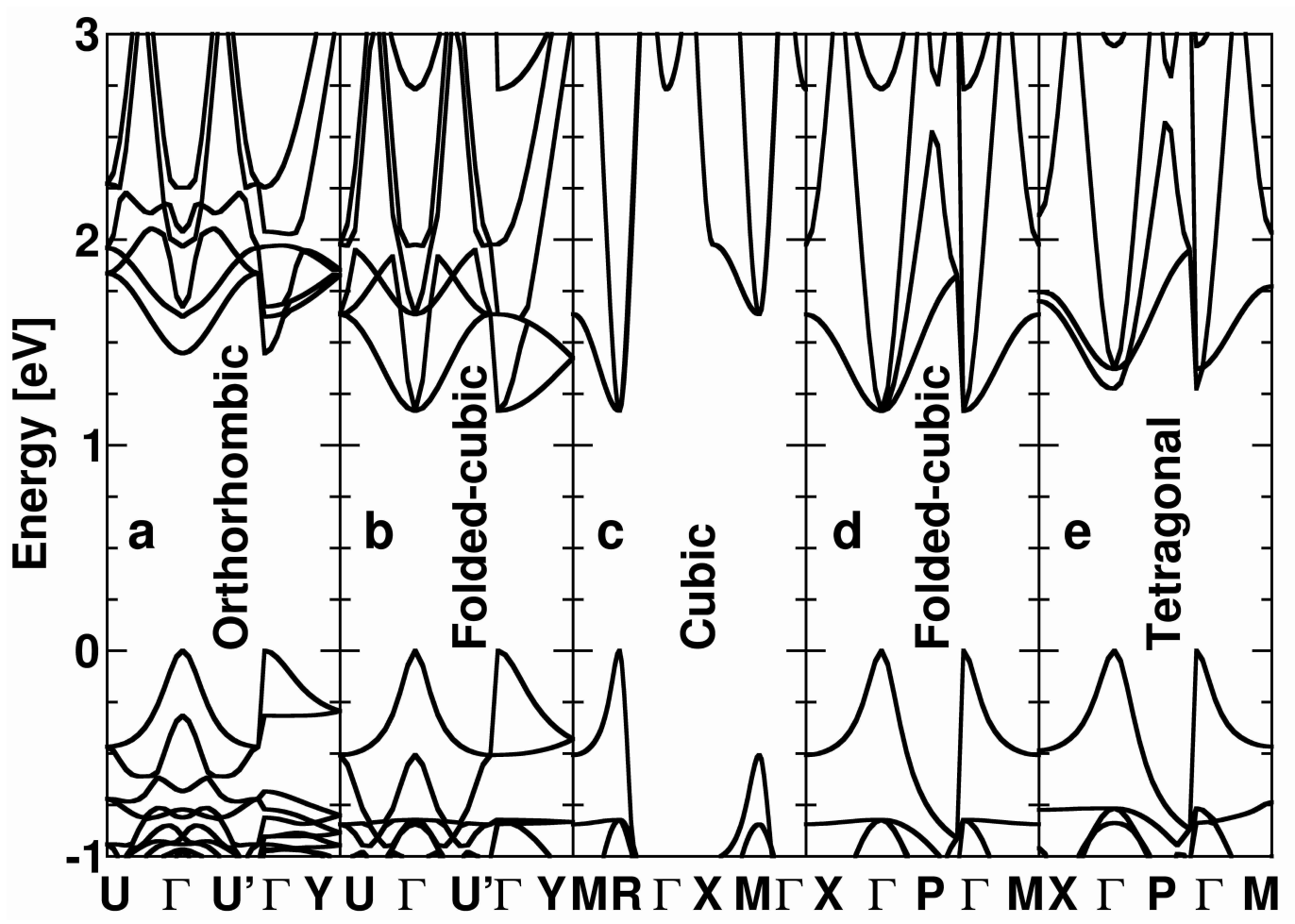

Figure 3. Band folding from the pseudo-cubic phase to the low temperature phases of $\mathrm{CH}_{3} \mathrm{NH}_{3} \mathrm{PbI}_{3}$. (a-c) Electronic band dispersion diagram for the Pm3m cubic phase of $\mathrm{CH}_{3} \mathrm{NH}_{3} \mathrm{PbI}_{3}$ : (c) in its $\mathrm{BZ}$, (b) folded back to the $\mathrm{BZ}$ of the Pnma orthorhombic phase, and (a) for the real Pnma orthorhombic phase of $\mathrm{CH}_{3} \mathrm{NH}_{3} \mathrm{PbI}_{3}$. (d) Electronic band dispersion diagram for the Pm3m cubic phase folded back to the BZ of the $\mathrm{I} / \mathrm{mcm}$ tetragonal phase and (e) for the real I $4 / \mathrm{mcm}$ tetragonal phase. The computation is performed at the LDA level of theory and SOC is not considered.

Next, the effect of the high to low temperature (Pm3m/Pnma) cell transformation in $\mathrm{CH}_{3} \mathrm{NH}_{3} \mathrm{PbI}_{3}$ can be explored by considering a $(\overrightarrow{\boldsymbol{a}}+\overrightarrow{\boldsymbol{b}}, 2 \overrightarrow{\boldsymbol{c}}, \overrightarrow{\boldsymbol{a}}-\overrightarrow{\boldsymbol{b}})$ supercell of the cubic lattice while keeping the atoms at the special positions of the Pm3m phase (Figure 3b, folded-cubic band structure). As the cell size is increased by a factor of $4(Z=4)$, it leads to a reduction of the $B Z$ volume by a 
factor of 4 . The electronic states close to the electronic band gap are folded from $\mathrm{R}$ of the cubic phase BZ to $\Gamma$ of the orthorhombic supercell BZ. This band folding effect clarifies the seeming complexity of the band diagram in the low temperature Pnma phase (Figure 3a). In addition, electronic states from $\mathrm{M}$ of the $\mathrm{Pm} 3 \mathrm{~m} \mathrm{BZ}$ are also folded back to $\Gamma$ and mixed with $\mathrm{R}$-states at the $\Gamma$ point of the low temperature Pnma BZ. This procedure reveals that, besides electronic band folding effect, the most important transformation of the diagram is due to atomic displacements. ${ }^{66}$ The increase of the electronic band gap is thus clearly induced by lattice distortions that are mainly related to tilts of the inorganic octahedra and space group symmetry reduction. ${ }^{83}$ Lattice transformations simultaneously lift the CBM degeneracy (Figure 3a). This is consistent with the group-subgroup relationship between the cubic Pm3m phase and the orthorhombic Pnma phase. Similarly, effects of band folding can be analyzed for the phase transition between the cubic Pm3m phase and, the tetragonal I4/mcm (Figure 3c-e). Here again, lattice distortions induced by octahedral tilt leads only to a partial lifting of the CBM degeneracy and are consistent with the space group symmetry reduction. ${ }^{74}$

More generally, the influence of strain ( $\varepsilon_{\mathrm{ij}}$ tensor) and degeneracy lifting can be understood and treated empirically within the $|\boldsymbol{X}\rangle,|\boldsymbol{Y}\rangle,|\boldsymbol{Z}\rangle$ basis of the simple group $\mathrm{T}_{1 \mathrm{u}}$ vectorial IR of the cubic $\mathrm{CBM}$ at $\mathrm{R},{ }^{74}$ by adding the following strain perturbation Hamiltonian to the multiband effective mass (k.p) Hamiltonian (equation 1):

$$
H_{\varepsilon}=\left(\begin{array}{ccc}
l \varepsilon_{x x}+m\left(\varepsilon_{y y}+\varepsilon_{z z}\right) & n \varepsilon_{x y} & n \varepsilon_{x z} \\
n \varepsilon_{x y} & l \varepsilon_{y y}+m\left(\varepsilon_{x x}+\varepsilon_{z z}\right) & n \varepsilon_{y z} \\
n \varepsilon_{x z} & n \varepsilon_{y z} & l \varepsilon_{z z}+m\left(\varepsilon_{x x}+\varepsilon_{y y}\right)
\end{array}\right)
$$


J. Phys. Chem. C, 2015, 119 (19), pp 10161-10177 DOI: 10.1021/acs.jpcc.5b00695

where $\varepsilon_{\mathrm{ij}}$ components of the lattice strain tensors are used and $l, m$ and $n$ parameters are deformation potentials that can be derived from experimental data or DFT results.

\section{IMPORTANCE OF SPIN ORBIT COUPLING IN 3D AND LAYERED HOP}

A giant SOC operates on the CB, which dominates the band gap of lead-based HOP, both for the high (Figure 4) and low temperature phases. ${ }^{66,74}$ About three times smaller for $\mathrm{CH}_{3} \mathrm{NH}_{3} \mathrm{SnX}_{3}$ than for $\mathrm{CH}_{3} \mathrm{NH}_{3} \mathrm{PbX}_{3}$, it remains sizeable in tin-based perovskites and the following conclusions apply both to lead and tin $\mathrm{HOP} .^{74}$ Recent analysis of tri-chlorides, $\mathrm{CH}_{3} \mathrm{NH}_{3} \mathrm{MCl}_{3}(\mathrm{M}=\mathrm{Pb}, \mathrm{Sn}$, Ge), show that SOC splittings are consistent with metal atomic energy level tables with an increase down group-14 of the periodic table. ${ }^{77}$ Moreover, SOC interactions stemming from halogens are shown to be sizable, especially for iodine-based perovskites, consistently with atomic data and computed atomic charges from the Atom In Molecules (AIM) quantum theory. ${ }^{77}$

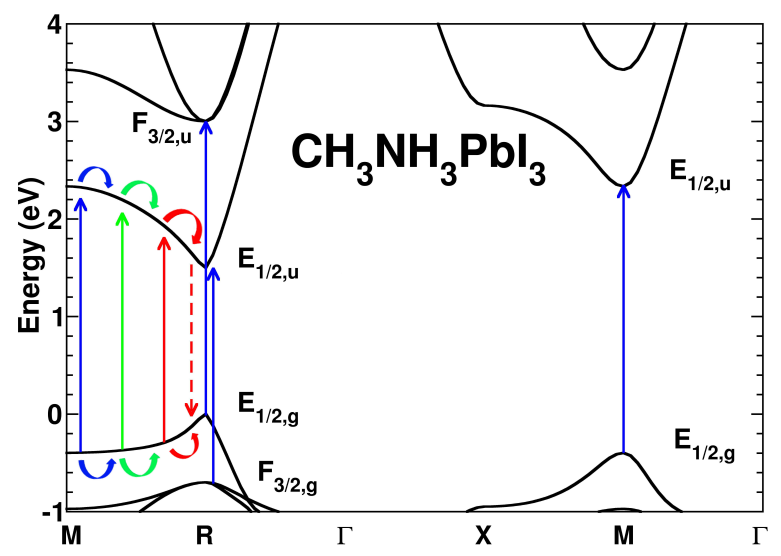


Figure 4. Electronic band structure for the high temperature cubic $\mathrm{Pm} 3 \mathrm{~m}$ phase of $\mathrm{CH}_{3} \mathrm{NH}_{3} \mathrm{PbI}_{3}$ with SOC at the LDA level of theory. An upward energy shift of $1.4 \mathrm{eV}$ has been applied to match the experimental bandgap value at R. Irreducible representations obtained from a Pm $3 \mathrm{~m}$ double group analysis, are given at $\mathrm{R}$ and $\mathrm{M}$ points for the electronic states close to the band gap. Vertical arrows show various possible optical transitions close to the band gap energy. Optical transitions along the line between the $\mathrm{M}$ and $\mathrm{R}$ points generate carriers that easily relax toward the R point. Reprinted with permission from ref 75. Copyright 2014 American Chemical Society.

In order to account for spin effect and lattice symmetry, a double space group description is needed. ${ }^{75}$ The starting point is the $|\boldsymbol{X}\rangle,|\boldsymbol{Y}\rangle,|\boldsymbol{Z}\rangle$ basis of the simple group $\mathrm{T}_{1 \mathrm{u}}$ vectorial IR of the cubic CBM at R and corresponding energy $\boldsymbol{E}_{C B M}^{0}$. At R, the spinor state basis at CBM converts into $|\boldsymbol{X} \uparrow\rangle,|\boldsymbol{Y} \uparrow\rangle,|\boldsymbol{Z} \uparrow\rangle,|\boldsymbol{X} \downarrow\rangle,|\boldsymbol{Y} \downarrow\rangle,|\boldsymbol{Z} \downarrow\rangle$ and SOC leads to an energy splitting $\Delta_{\text {so }}$. CBM becomes a two-fold degenerate spin-orbit split-off (SO) state whose energy reads $\boldsymbol{E}_{(\boldsymbol{S O})}=\boldsymbol{E}_{\boldsymbol{C B M}}^{0}-2 \Delta_{\boldsymbol{S O}} / 3$. The remaining four-fold degenerate CB states undergo an upward energy shift: $\boldsymbol{E}=\boldsymbol{E}_{\boldsymbol{C B M}}^{0}+\Delta_{S o} / 3$

In other words, the simple group $\mathrm{T}_{1 \mathrm{u}}$ vectorial representation of the $\mathrm{CBM}$ at $\mathrm{R}$ is split in a doubly degenerated $E_{1 / 2 u}\left(\mathrm{SO}\right.$ states) and a fourfold degenerated $\mathrm{F}_{3 / 2 \mathrm{u}}$ state as illustrated in Figure 4. The ground state isotropic optical transition is thus predicted at $\mathrm{R}$ between doubly degenerated $\mathrm{E}_{1 / 2 \mathrm{~g}}$ VBM and $\mathrm{E}_{1 / 2 \mathrm{u}} \mathrm{CBM}$ states. At $\mathrm{R}$, a series of other transitions are optically allowed, the lowest in energy corresponding to two secondary transitions $\mathrm{F}_{3 / 2 \mathrm{~g}} \rightarrow \mathrm{E}_{1 / 2 \mathrm{u}}$ and $\mathrm{E}_{1 / 2 \mathrm{~g}} \rightarrow \mathrm{F}_{3 / 2 \mathrm{u}}$ (Figure 4). The transition between the doubly degenerated $E_{1 / 2 g} V B$ and $E_{1 / 2 u} C B$ states at $M$ is also optically allowed and polarized with transverse isotropy. A total isotropic activity is found for the transition at the $\mathrm{M}$ point in the pseudo-cubic phase by considering that the star of the $\mathbf{k}_{\mathrm{M}}$ point contains three arms.$^{75}$ Inclusion of SOC leads to a dramatic reduction of oscillator strengths that decreases to $17 \mathrm{eV}$ for the fundamental transition at $\mathrm{R} \cdot{ }^{75}$ In terms of Kane energy, it drops to $c a 6$ $\mathrm{eV}$ which is about four times smaller than that of GaAs, thus evidencing an additional difference between HOP and conventional semiconductors. 

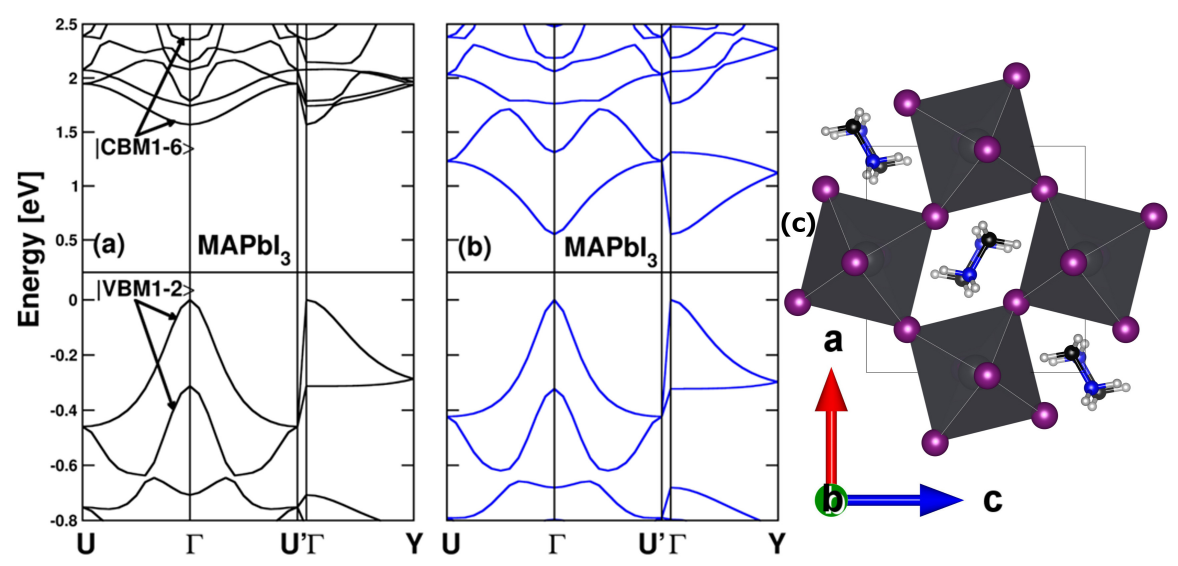

Figure 5. Electronic band structure of $\mathrm{CH}_{3} \mathrm{NH}_{3} \mathrm{PbI}_{3}\left(\mathrm{MAPbI}_{3}\right)$ in the low temperature orthorhombic Pnma phase (a) without and (b) with SOC at the GGA level of theory with the ABINIT code. The energy levels are referenced to the valence band maximum. (c) Overview of the crystal structure. Reprinted with permission from ref 66. Copyright 2013 American Chemical Society.

Impact of SOC can be further analyzed by comparing the electronic structures of pseudocubic Pm3m, orthorhombic (Figure 5) and tetragonal phases of $\mathrm{CH}_{3} \mathrm{NH}_{3} \mathrm{PbI}_{3}{ }^{74}$ These dispersion diagrams can be empirically rationalized by considering the spinor state basis and adding a perturbation Hamiltonian accounting for SOC to the k.p multiband Hamiltonian of the CBM close to the critical point $\mathrm{R}$ of the cubic BZ (equation 1) and the perturbative strain Hamiltonian (equation 2). Noteworthy, the lattice distortion at the cubic-tetragonal phase transition combined with SOC leads to a complete splitting of the vectorial representation, whereas only a partial splitting is predicted when the SOC is neglected (Figure 3e) ${ }^{74}$ Indeed for such a tetragonal lattice distortion, the three eigenvalues of the total Hamiltonian including all effects are doubly degenerated and can be analytically calculated at the critical point of the BZ (R-point in the cubic phase):

$$
\begin{aligned}
& E_{0}=E_{C B}^{0}+(l+m) \varepsilon_{x x}+m \varepsilon_{z z}+\Delta_{S O} / 3 \\
& E_{ \pm}=E_{0}-\frac{\delta E+\Delta_{S O}}{2} \pm \sqrt{\left(\frac{\delta E-\Delta_{S O} / 3}{2}\right)^{2}+2 \Delta_{S O}^{2} / 9}
\end{aligned}
$$


with $\boldsymbol{\delta} E=(\boldsymbol{l}-\boldsymbol{m})\left(\boldsymbol{\varepsilon}_{x \boldsymbol{x}}-\boldsymbol{\varepsilon}_{z z}\right)$. The effect of strain is systematically smaller than that induced by SOC in lead halide compounds. If SOC is neglected $\left(\Delta_{\mathrm{SO}}=0\right.$ in equation 3$)$, one of the CBM eigenvalues remains doubly degenerated (Figure 3e).

The most important effect of SOC is the reduction of the DOS in the conduction band by a factor of 3 as compared to DOS calculated without SOC. ${ }^{74,75}$ This DOS reduction has a deep impact on both transport and optical properties, which leads to a net reduction of the optical absorption by the same amount. However, since both valence and conduction bands are now associated with two dispersion parabola with almost the same effective masses (i.e. band curvatures), ${ }^{89,92}$ wellbalanced carrier transport is obtained for both electrons and holes. Moreover, the optical absorption is related to the joint density of states close to the critical R-point, and thus to reduced mass $\mu$. This quantity is smaller in GaAs than in 3D HOP, because the mass of the hole and of the electron, are respectively larger and smaller. This important property directly connected to SOC adequately compensates the smaller Kane energy (oscillator strength) of 3D HOP. ${ }^{75}$

When including SOC, the calculated band-gaps of 3D HOP appear substantially under-estimated. This is a well-known limitation of DFT that can be corrected by including many-body effects using GW self-energy corrections for the band gap ${ }^{66}$ and the Bethe-Salpeter equation for the exciton. ${ }^{74}$ Accurate GW self-energy corrections have been reported by several research groups. ${ }^{80,92,108}$ These affords more accurate effective masses of the carrier both for conventional semiconductors and HOP. 
J. Phys. Chem. C, 2015, 119 (19), pp 10161-10177 DOI: 10.1021/acs.jpcc.5b00695
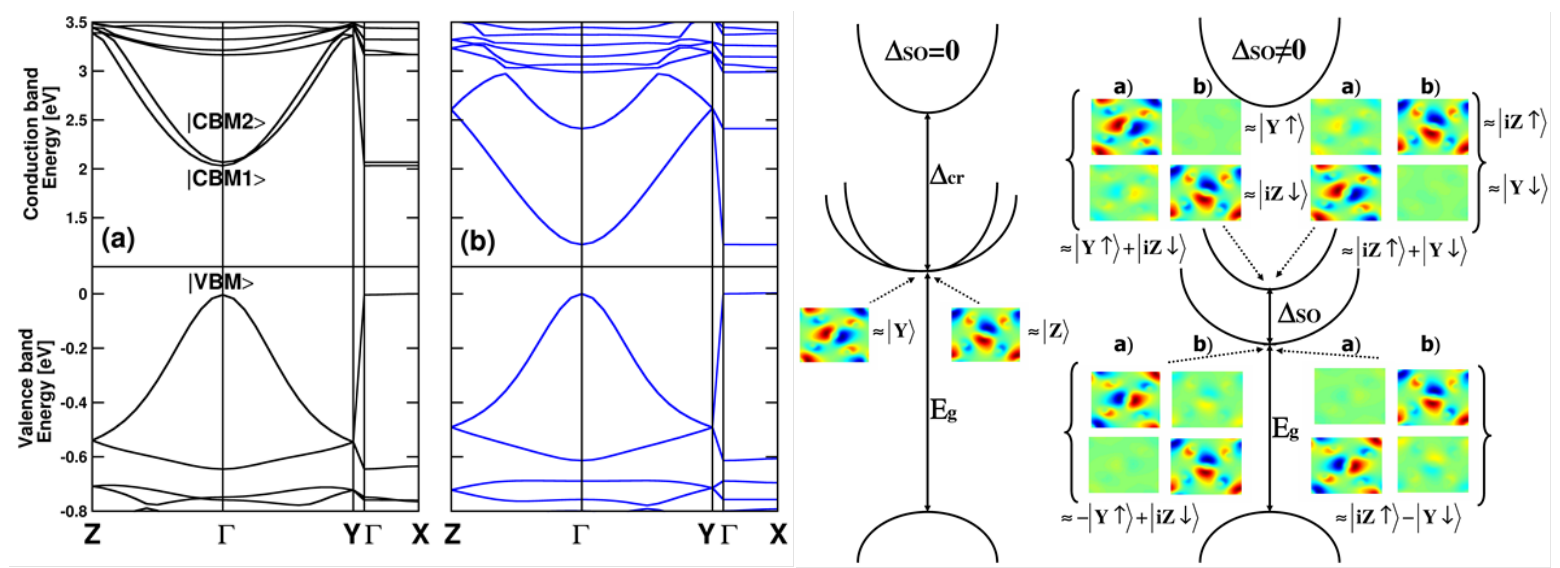

Figure 6. (left) Electronic band structure of the layered $\mathrm{HOP}\left(\left[\mathrm{pFC}_{6} \mathrm{H}_{5} \mathrm{C}_{2} \mathrm{H}_{4} \mathrm{NH}_{3}\right]_{2} \mathrm{PbI}_{4}\right)$, (a) without and (b) with SOC at the GGA level of theory with the ABINIT code. ${ }^{61}$ Energy levels are referenced to the valence band maximum. (right) General schematic representations of a layered HOP electronic band diagram without and with SOC $\left(\Delta_{\mathrm{SO}}\right) . \Delta_{\mathrm{cr}}$ represents the anisotropy of the crystal field. This panel includes the a) real and b) imaginary parts of the complex spinorial components of the first and second CBM states with spin up component on top of the spin down component. Reprinted with permission from ref 61. Copyright 2012 American Physical Society.

Similar effects are predicted for layered HOP with the important difference that the CBM without SOC is only twice degenerated. ${ }^{61}$ SOC leads to a non-degenerate state at the CBM, and band dispersion at both CBM and VBM correspond to parabola (Figure 6) in a favorable configuration for optical activity. The study of the monocrystalline $\left[\mathrm{pFC}_{6} \mathrm{H}_{5} \mathrm{C}_{2} \mathrm{H}_{4} \mathrm{NH}_{3}\right]_{2} \mathrm{PbI}_{4}$ as a model for layered HOP demonstrates that the optical process is governed by three active Bloch states at the $\Gamma$ point of the reduced BZ (two Bloch states for the CBM and one for the VBM) with a reverse ordering compared to anisotropically bonded semiconductors. Giant spin-orbit coupling effects (Figure 6d) and optical activities can be subsequently inferred from symmetry analysis. Transverse electric (TE) optical activity has indeed been predicted theoretically, ${ }^{61}$ in good agreement with previous experimental results. ${ }^{1}$ TE optical activity indicates that the light is absorbed at the band gap energy only for an electrical polarization parallel to the layer.

\section{LOSS OF INVERSION SYMMETRY AND INTERPLAY WITH SOC IN HOP}


The room (high)-temperature crystal structure of 3D HOP remains under debate. For long time it was assumed that it is a $\mathrm{Pm} 3 \mathrm{~m}$ pseudo-cubic phase, with dynamical disorder of the organic cations $\mathrm{CH}_{3} \mathrm{NH}_{3}{ }^{+124}$ Recent single crystal X-ray diffraction experiments, performed on $\mathrm{CH}_{3} \mathrm{NH}_{3} \mathrm{MI}_{3}$ close to room temperature, support a non-centrosymmetric tetragonal space group (P4mm, no 99). ${ }^{29}$ These compounds exhibit a phase transition to a tetragonal noncentrosymmetric and centered $\mathrm{I} 4 \mathrm{~cm}$ phase (no 108), ${ }^{29}$ instead of the previously reported symmetric $\mathrm{I} 4 \mathrm{mcm}$ phase (no 140). ${ }^{124}$ This phase transition is associated to a group-subgroup relationship between $\mathrm{P} 4 \mathrm{~mm}$ and $\mathrm{I} 4 \mathrm{~cm}$, similar to the previously proposed $\mathrm{Pm} 3 \mathrm{~m}-\mathrm{I} 4 / \mathrm{mcm}$ phase sequence analyzed for $\mathrm{CH}_{3} \mathrm{NH}_{3} \mathrm{PbI}_{3}$ and $\mathrm{CH}_{3} \mathrm{NH}_{3} \mathrm{PbBr}_{3} .{ }^{124}$ For $\mathrm{CH}_{3} \mathrm{NH}_{3} \mathrm{PbI}_{3}$, this transition occurs above room temperature $\left(\mathrm{T}_{\mathrm{c}}=333 \mathrm{~K}\right)$.

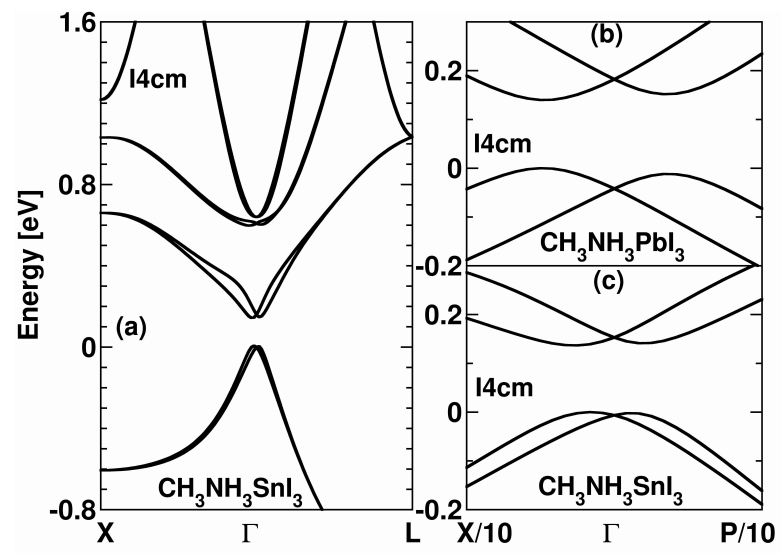

Figure 7. (a) Band structure of the I4cm phase of $\mathrm{CH}_{3} \mathrm{NH}_{3} \mathrm{SnI}_{3}$ at the LDA level of theory with SOC and zoom close to the critical $\Gamma$ point, (b) for $\mathrm{CH}_{3} \mathrm{NH}_{3} \mathrm{PbI}_{3}$ and (c) for $\mathrm{CH}_{3} \mathrm{NH}_{3} \mathrm{SnI}_{3}$ showing the Rashba-Dresselhaus-like spinor splitting due to the loss of inversion symmetry. Reprinted with permission from ref 74. Copyright 2014 John Wiley and Sons.

The loss of the inversion symmetry combined with SOC is known to induce a splitting of the spinor bands away from the critical point $\Gamma$ of the BZ in zinc-blende and würtzite structures ${ }^{125}$ It was shown, that even a small symmetry breaking might lead to a strong spinor splitting in 3D 


\section{J. Phys. Chem. C, 2015, 119 (19), pp 10161-10177 DOI: 10.1021/acs.jpcc.5b00695}

HOP, since the SOC effect is giant by comparison to conventional semiconductors. ${ }^{74}$ Indeed, the electronic band diagram of the $\mathrm{P} 4 \mathrm{~mm}$ phase of both $\mathrm{CH}_{3} \mathrm{NH}_{3} \mathrm{MI}_{3} \mathrm{HOPs}$ close to the critical point A (corresponding to $\mathrm{R}$ of the ideal cubic phase) exhibits a splitting of the spinor bands, even though the deviation from the centrosymmetric $\mathrm{Pm} 3 \mathrm{~m}$ phase is small. ${ }^{74}$ This effect is more important for the tetragonal I4 $\mathrm{cm} \mathrm{CH}_{3} \mathrm{NH}_{3} \mathrm{PbI}_{3}$ and $\mathrm{CH}_{3} \mathrm{NH}_{3} \mathrm{SnI}_{3} 3 \mathrm{D}$ HOP (Figure 7). ${ }^{74}$ The bands are folded from A to $\Gamma$. This result was confirmed and analyzed, using different DFT approaches and subsequent many-body corrections. ${ }^{83,92,114}$ This effect still deserves some experimental investigation, and various names were used for the interplay between SOC and loss of inversion symmetry in 3D HOP: "band splitting", ${ }^{74}$ Rashba/Dresselhaus, ${ }^{83}$ Dresselhaus, ${ }^{83}$ Rashba. ${ }^{114}$ Besides, we underline that most works on the low temperature phase of $\mathrm{CH}_{3} \mathrm{NH}_{3} \mathrm{PbI}_{3}$ use a refined centrosymmetric orthorhombic Pnma structure. However, the structure of the low temperature-phase of $\mathrm{CH}_{3} \mathrm{NH}_{3} \mathrm{MI}_{3}$ is still debated: alternative monoclinic, triclinic or noncentrosymmetric Pna21 (no 33) orthorhombic space groups have been suggested, which might also lead to spinor band splitting away from critical points of the BZ.

\section{QUANTUM CONFINEMENT AND BAND ALIGNEMENT IN LAYERED HYBRID PEROVSKITES}

Most available theoretical studies of layered HOP either give a general description of the electronic band structure, mostly using DFT, $5,57,61$ or focus on the excitonic coupling using effective mass parameters for the carrier dispersion and abrupt dielectric confinement schemes. ${ }^{126,127}$ HOP are very large systems for DFT simulations, and may not be readily simulated due to computational resources limitations. A fruitful schematic representation was proposed earlier for the layered HOP, introducing the quantum well (QW) concept. ${ }^{11}$ This 
qualitative picture is based on the observation that these HOP are built from semiconducting inorganic sheets alternating with organic layers having much wider band gaps. It has led a qualitative picture of a type-I QW-like heterostructure but without quantitative evaluation of the quantum confinement effect.
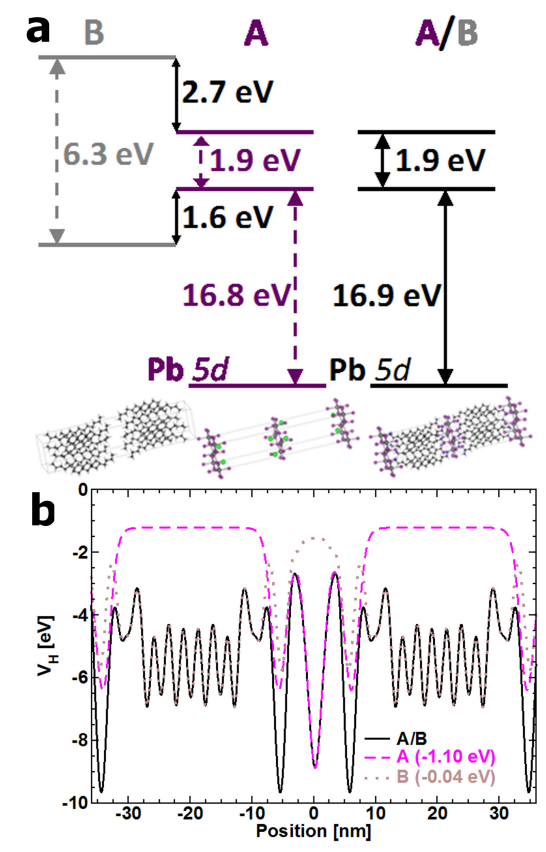

Figure 8. (a) Schematic representation of the $\mathrm{CB}$ and $\mathrm{VB}$ band alignment considering the $\left(\mathrm{C}_{10} \mathrm{H}_{21} \mathrm{NH}_{3}\right)_{2} \mathrm{PbI}_{4}$ layered $\mathrm{HOP}(\mathrm{A} / \mathrm{B})$ as a composite structure made of $\mathrm{A}$ and $\mathrm{B}$ modeled by $(\mathrm{Na})_{2} \mathrm{PbI}_{4}$ and $\mathrm{C}_{10} \mathrm{H}_{21} \mathrm{CH}_{3}$, respectively. (b) Computed potential profiles for the real layered material (A/B, straight line) and A (dashed line) and B (dotted line) bulk-like materials. Band alignment and match of potential profiles of $\mathrm{A} / \mathrm{B}$ are obtained thanks to downward shifts of the data computed for $\mathrm{A}$ and $\mathrm{B}$ amounting to 1.1 and $0.04 \mathrm{eV}$, respectively. Alignment of $\mathrm{Pb} 5 \mathrm{~d}$ orbitals between $\mathrm{A} / \mathrm{B}$ and $\mathrm{A}$ also require a $1.1 \mathrm{eV}$ shift. Computations were performed at the GGA level of theory with the SIESTA code. Reprinted with permission from ref 128. Copyright 2014 John Wiley and Sons.

However, quantitative description of layered HOP faces a special problem. ${ }^{128}$ In fact, defining the $\mathrm{A} / \mathrm{B}$ heterostructure (the layered HOP) is straightforward, but the A and B bulk partners are not easily defined. A reverse situation applies in heterostructures grown from conventional semiconductors, since in this case the A and B bulk partners are usually well-defined, whereas the $\mathrm{A} / \mathrm{B}$ heterostructure (a $\mathrm{QW}$ for example) deserves experimental or theoretical investigations 


\section{J. Phys. Chem. C, 2015, 119 (19), pp 10161-10177 DOI: 10.1021/acs.jpcc.5b00695}

to capture accurately effects of strain or interfaces. ${ }^{123}$ At a first glance, A and B of layered HOP may be roughly defined as the inorganic and organic layers, respectively. It is however not conceptually possible to identify the $\mathrm{A}$ and $\mathrm{B}$ bulk partners with the inorganic $\mathrm{PbI}_{4}{ }^{2-}$ layer and the sheet of organic cations, respectively, because the Coulomb interactions have a large impact on the electronic structure of the hybrid material, especially for electronic states located close to the electronic band gap.

A description of the whole layered HOP structure as a composite material in a slightly different way leads to a rigorous composite approach to compute the valence band-lineup of layered HOP. ${ }^{128}$ It is illustrated for $\left(\mathrm{C}_{10} \mathrm{H}_{21} \mathrm{NH}_{3}\right)_{2} \mathrm{PbI}_{4}$ in Figure 8. Structure A corresponds to an inorganic $\mathrm{PbI}_{4}{ }^{2-}$ perovskite layer with additional $\mathrm{Na}$ cations. The latter are located at the position of the nitrogen atom of each organic cation, so as to mimic the strong Coulomb interactions close to the inorganic layer. This procedure is similar to the one described in section 3 for $3 \mathrm{D}$ HOP. Structure B is made from organic neutral molecules, namely $\mathrm{C}_{10} \mathrm{H}_{21} \mathrm{CH}_{3}$, where nitrogen has been replaced by a carbon atom, thus ensuring electroneutrality and avoiding electron double counting. This analysis shows that layered HOP can be considered as composite materials with very weak interactions between the inorganic layers, with a reconstruction of the whole Hartree potential profile by pieces. This procedure also affords the complete conduction and valence band alignments of $\mathrm{A}$ and $\mathrm{B}$ "bulk like" materials with respect to each other and leads to a confinement potential both for holes and electrons in the inorganic layer. Interestingly, alignment of the $\mathrm{Pb} 5 d$ orbitals of both structures is obtained by applying the very same offsets. In fact, $\mathrm{Pb}$ $5 d$ orbitals are low lying orbitals virtually unaffected by chemical substitution in such HOP and have already been suggested to offer an electronic marker to deduce absolute VB energies. ${ }^{66}$ It gives a first quantitative basis to the schematic picture initially proposed by Mitzi and 
J. Phys. Chem. C, 2015, 119 (19), pp 10161-10177 DOI: 10.1021/acs.jpcc.5b00695

coworkers. ${ }^{11}$ It should be noted that this quantitative approach for layered HOP can be extended to other classes of 2D functional materials. ${ }^{128}$

It is quite tempting to apply effective mass models based on an ultrathin quantum well with finite confinement barriers for carriers, in order to predict quantum confinement effects in layered HOP. ${ }^{129}$ In fact, these empirical models predict superlattice (SL) effects that are not observed experimentally or in DFT simulations. ${ }^{61,128}$ A first fundamental limitation of such approaches is that the computed energies of the confined charge carriers lie in a range where strong nonparabolicity occurs. ${ }^{128}$ Indeed, the commonly used reference bulk material, namely $\left(\mathrm{CH}_{3} \mathrm{NH}_{3}\right) \mathrm{PbI}_{3}$, taken for the inorganic $\mathrm{QW}^{129}$ is inappropriate. ${ }^{128}$ An even more important limitation is that the effective mass model for conventional semiconductor heterostructures is linked with a definition of envelope functions to describe the electronic eigenfunctions of the whole heterostructure:

$$
\psi(\boldsymbol{r})=\sum_{n} F_{n}(\boldsymbol{r}) U_{n}(\boldsymbol{r}),
$$

where $F_{n}(\boldsymbol{r})$ are expected to be slowly varying functions and $U_{n}(\boldsymbol{r})$ are periodic and rapidly oscillating functions. In order to further simplify the theoretical approach, the envelope function approximation (EFA) is usually implemented in these heterostructures. This approximation relies on the assumption that many conventional bulk semiconductors are similar in their chemical nature, and that the Bloch functions of the bulk materials at high symmetry points of the BZ differ only slightly. At the $\Gamma$ point, it corresponds to the following approximation:

$$
U_{n}(\boldsymbol{r}) \approx U_{n, 0}^{A}(\boldsymbol{r}) \approx U_{n, 0}^{B}(\boldsymbol{r})
$$

If this condition is verified, boundary conditions related to the $\mathrm{A} / \mathrm{B}$ heterostructure, namely $\psi(\boldsymbol{r})$ total wavefunction matching and current conservation, are reduced to the envelope 
functions only. For a simple effective mass model in a A/B 2D structure perpendicular to the $z$ axis having its interface at $z=z_{i}$ :

$F_{n}^{A}\left(z_{i}\right)=F_{n}^{B}\left(z_{i}\right)$

$\left.\frac{1}{m^{A}} \frac{d F_{n}^{A}(z)}{d z}\right|_{z=z_{i}}=\left.\frac{1}{m^{B}} \frac{d F_{n}^{B}(z)}{d z}\right|_{z=z_{i}}$

The condition on the Bloch functions of A and B partners (equation 5) is obviously not fulfilled in layered hybrid perovskites. The confinement potentials are correctly defined but cannot be combined with effective mass modeling to predict quantum confinement effects. ${ }^{128}$ Thus, DFT remains the best tool to explore theoretically electronic properties of layered HOP ${ }^{61}$

\section{QUANTUM CONFINEMENT AND BAND ALIGNMENT IN 3D HYBRID PEROVSKITE HETEROSTRUCTURES}

Heterostructures built from 3D HOP have not yet been explored experimentally, but may afford interesting possibilities for bang gap engineering and tuning of the optical and transport properties. The electronic band dispersion diagrams of two short SL of $\mathrm{CH}_{3} \mathrm{NH}_{3} \mathrm{PbI}_{3} / \mathrm{CH}_{3} \mathrm{NH}_{3} \mathrm{PbBr}_{3}$ are compared in Figure 9. The stacking axis for the two SL correspond to the long axis (b) of pure $\mathrm{CH}_{3} \mathrm{NH}_{3} \mathrm{PbI}_{3}$ and $\mathrm{CH}_{3} \mathrm{NH}_{3} \mathrm{PbBr}_{3}$ in their low temperature Pnma orthorhombic phases. The electronic dispersions of the two SL along the $\Gamma-Y$ direction are more flat than for pure compounds, indicative of quantum confinement. Thus, the $\mathrm{CH}_{3} \mathrm{NH}_{3} \mathrm{PbI}_{3}$ domain of a $\mathrm{CH}_{3} \mathrm{NH}_{3} \mathrm{PbI}_{3} / \mathrm{CH}_{3} \mathrm{NH}_{3} \mathrm{PbBr}_{3} \mathrm{SL}$ can be considered as a QW.

This finding is consistent with the $\mathrm{CB}$ and $\mathrm{VB}$ confinement potentials reported recently in this system $(0.09 \mathrm{eV}$ in the $\mathrm{CB}$ and $0.26 \mathrm{eV}$ in the $\mathrm{VB}) .{ }^{93}$ However, the electronic dispersions along the $\Gamma$-Y direction are not completely flat (Figure 9) like in a 2D layered HOP (Figure 6). This is a clear indication that the wavefunctions both in $\mathrm{CB}$ and $\mathrm{VB}$ are coupled from $\mathrm{CH}_{3} \mathrm{NH}_{3} \mathrm{PbI}_{3} \mathrm{QW}$ 
to $\mathrm{CH}_{3} \mathrm{NH}_{3} \mathrm{PbI}_{3} \mathrm{QW}$ (so-called SL effect), and are delocalized across the $\mathrm{CH}_{3} \mathrm{NH}_{3} \mathrm{PbBr}_{3}$ barrier. This is confirmed when plotting along the SL axis, the electronic density of the VBM of the short SL (SL2) containing two $\mathrm{CH}_{3} \mathrm{NH}_{3} \mathrm{PbI}_{3}$ cells and one $\mathrm{CH}_{3} \mathrm{NH}_{3} \mathrm{PbBr}_{3}$ cell (Figure 10). The electronic density is maximum in the $\mathrm{CH}_{3} \mathrm{NH}_{3} \mathrm{PbI}_{3} \mathrm{QW}$, but non-zero in the $\mathrm{CH}_{3} \mathrm{NH}_{3} \mathrm{PbBr}_{3}$ barrier.

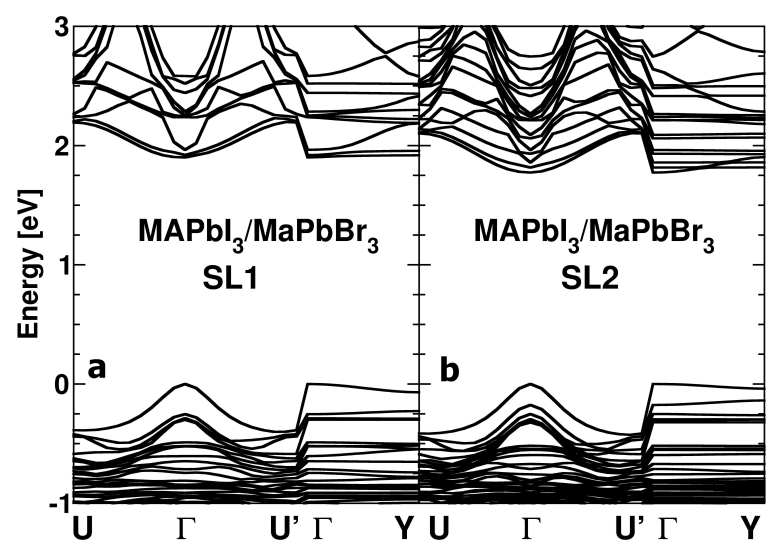

Figure 9. Electronic band dispersion diagrams of (a) a short SL (SL1) containing one $\mathrm{CH}_{3} \mathrm{NH}_{3} \mathrm{PbI}_{3}$ cell and one $\mathrm{CH}_{3} \mathrm{NH}_{3} \mathrm{PbBr}_{3}$ cell, and (b) a second short SL (SL2) containing two $\mathrm{CH}_{3} \mathrm{NH}_{3} \mathrm{PbI}_{3}$ cells and one $\mathrm{CH}_{3} \mathrm{NH}_{3} \mathrm{PbBr}_{3}$ cell. The diagrams are computed at the DFT level with a GGA exchange-correlation functional. SOC is not considered.

Moreover, one may notice that the electronic density variation is based on the same repeated pattern close to lead atoms (Figure 10a). This pattern is characteristic of the VBM Bloch functions of both $\mathrm{CH}_{3} \mathrm{NH}_{3} \mathrm{PbI}_{3}$ and $\mathrm{CH}_{3} \mathrm{NH}_{3} \mathrm{PbBr}_{3} 3 \mathrm{D}$ bulk $\mathrm{HOP}$. ${ }^{66}$ The $U_{n}(\boldsymbol{r}) \approx U_{n, \mathbf{0}}^{A}(\boldsymbol{r}) \approx$ $U_{n, 0}^{B}(\boldsymbol{r})$ condition (equation 5) is thus fulfilled with $\mathrm{A}=\mathrm{CH}_{3} \mathrm{NH}_{3} \mathrm{PbI}_{3}$ and $\mathrm{B}=\mathrm{CH}_{3} \mathrm{NH}_{3} \mathrm{PbBr}_{3}$. We may thus infer that the EFA is justified for an heterostructure built from 3D HOP. We must point out that computation of the electronic properties, including quantum confinement and electronic band gap opening, are only qualitatively computed at the DFT level, since the effective masses at $\mathrm{CBM}$ and VBM are not well predicted at this level of theory. Figure 10c is a representation of the $\mathrm{CBM}$ and VBM energies computed for a single $\mathrm{CH}_{3} \mathrm{NH}_{3} \mathrm{PbI}_{3} / \mathrm{CH}_{3} \mathrm{NH}_{3} \mathrm{PbBr}_{3} \mathrm{QW}$ within the EFA as a function of the QW thickness. The effective masses were taken from ref. 92 (DFT 
including GW corrections) and the quantum confinement potentials from ref. 93. The quantum confinement effect is expected to show off mostly for $\mathrm{CH}_{3} \mathrm{NH}_{3} \mathrm{PbI}_{3} \mathrm{QW}$ thicknesses below $4 \mathrm{~nm}$, where the correction to the band gap is larger than $0.1 \mathrm{eV}$. This is consistent with the fact that the DFT computation for SL2 (Figure 9b) is different from that of bulk $\mathrm{CH}_{3} \mathrm{NH}_{3} \mathrm{PbI}_{3}$ (Figure 5a).
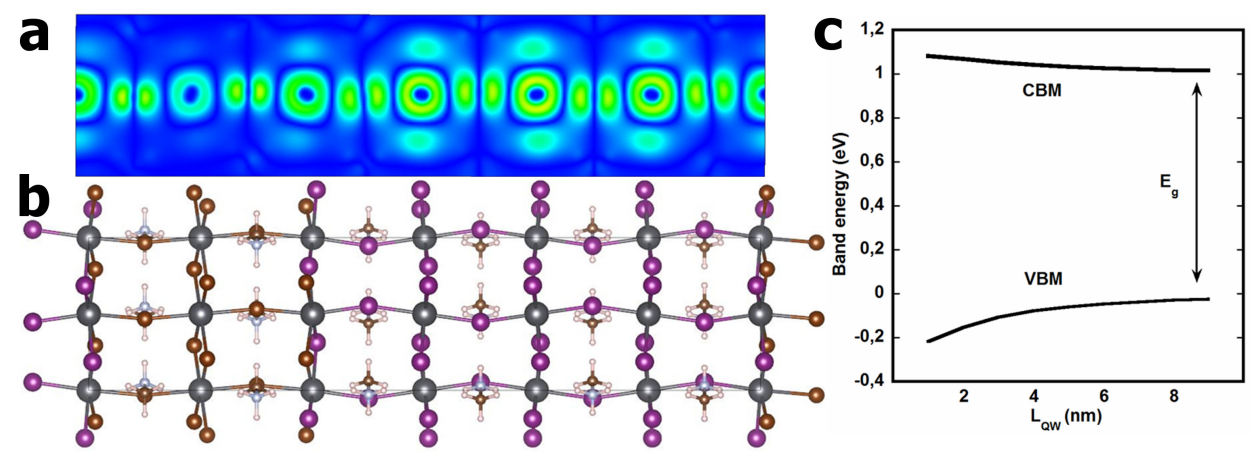

Figure 10. (a) Representation of the electronic density for the VBM of the short superlattice SL2 containing two $\mathrm{CH}_{3} \mathrm{NH}_{3} \mathrm{PbI}_{3}$ cells and one $\mathrm{CH}_{3} \mathrm{NH}_{3} \mathrm{PbBr}_{3}$ cell (Figure 9). (b) Overview of the atomic structure. The diagrams are computed at the DFT level with a GGA exchange-correlation functional. SOC is not considered. (c) Electron (CBM) and hole (VBM) ground state energies as a function of QW thickness computed with effective masses and confinement potentials.

\section{EXCITONIC PROPERTIES OF 3D AND LAYERED HYBRID PEROVSKITES}

Excitonic effects in 3D HOP can be accounted for using the Bethe-Salpeter Equation (BSE) starting from the monoelectronic states calculated at the DFT level. When taking the high temperature cubic phases of $\mathrm{CH}_{3} \mathrm{NH}_{3} \mathrm{PbI}_{3}$ and $\mathrm{CH}_{3} \mathrm{NH}_{3} \mathrm{PbCl}_{3}$ enhancement of absorption at the bandgap was clearly evidenced in the first BSE simulations reported in the literature (Figure 11). ${ }^{74}$ In the perturbative BSE/DFT approach, screening of the electron-hole interaction due to atomic motion ${ }^{75}$ is however not taken into account. Thus it is more suited to the low temperature phases where these motions are frozen. Such calculations are computationally more demanding and only resonant states may be addressed accurately. ${ }^{117}$ This means that at higher temperature experimental results on the exciton cannot be fully understood from BSE /DFT calculations, if atomic motions are important. 


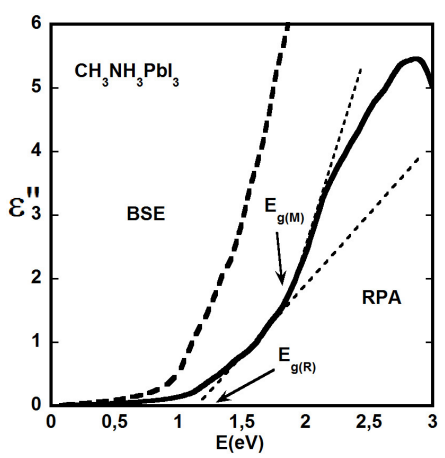

Figure 11. Comparison of the dielectric constant variation of $\mathrm{CH}_{3} \mathrm{NH}_{3} \mathrm{PbI}_{3}$ in the cubic phase with (dotted line, BSE calculation) and without (straight line, RPA calculation) the excitonic interaction. Onsets of optical transitions at $\mathrm{R}$ and $\mathrm{M}$ points are indicated. Reprinted with permission from ref 74. Copyright 2014 John Wiley and Sons.

Given the large carrier mobilities reported for 3D HOP at room temperature, it prompts the question of the nature of photoexcited species: are they free charges or excitons? If excitons, what role do they play in transport properties $?^{75}$ Importance and origin of exciton screening can be gauged from experimental absorption spectra of $\mathrm{CH}_{3} \mathrm{NH}_{3} \mathrm{PbI}_{3}$ recorded two decades ago by Ishihara et al (Figure 12).,75 These data are consistent with an exciton quenching between $159 \mathrm{~K}$ and $212 \mathrm{~K}$, in relation with the structural transition at $\mathrm{T}_{\mathrm{c}}=162 \mathrm{~K}$. The exciton quenching includes both exciton screening and gap-switching (ill-named exciton-switching), that also appears in 2D hybrids. A convenient way to simulate exciton screening is to consider a two-particle wave function $\psi\left(\boldsymbol{r}_{e}, \boldsymbol{r}_{\boldsymbol{h}}\right)$, where $\boldsymbol{r}_{\boldsymbol{e}}\left(\boldsymbol{r}_{\boldsymbol{h}}\right)$ is the electron (hole) position. The effective mass approximation works well close to the bandgap in $3 \mathrm{D}$ HOP both for electrons and holes, thanks to the giant SOC in the CB leading to a non-degenerate band instead of a triply degenerate one obtained without SOC. For a Wannier exciton, the two-particle Hamiltonian including electrostatic interaction and effective mass approximation for electrons and holes reads:

$$
\boldsymbol{H}=\boldsymbol{E}_{g}-\frac{\hbar^{2}}{2 \boldsymbol{m}_{e}} \Delta_{r e}-\frac{\hbar^{2}}{2 \boldsymbol{m}_{\boldsymbol{h}}} \Delta_{r \boldsymbol{h}}-\frac{\boldsymbol{e}^{2}}{4 \pi \varepsilon_{e f f}\left|\boldsymbol{r}_{e}-\boldsymbol{r}_{\boldsymbol{h}}\right|}
$$


$\boldsymbol{E}_{g}$ is the bandgap energy, $\boldsymbol{\varepsilon}_{\text {eff }}$ the effective dielectric constant and $\boldsymbol{m}_{\boldsymbol{e}}\left(\boldsymbol{m}_{\boldsymbol{h}}\right)$ the electron (hole) effective mass. Introducing the center-of-mass coordinate $\boldsymbol{R}=\frac{\boldsymbol{m}_{e} \boldsymbol{r}_{e}+\boldsymbol{m}_{\boldsymbol{h}} \boldsymbol{r}_{\boldsymbol{h}}}{\boldsymbol{m}_{e}+\boldsymbol{m}_{\boldsymbol{h}}}$ and the difference coordinate $r=r_{e}-r_{h}$, the general solution becomes of separable form, $\psi\left(r_{e}, r_{h}\right)=\frac{e^{i K . R}}{\sqrt{V}} \varphi(r)$, where $\varphi(\boldsymbol{r})$ is the wave function for the relative motion. The corresponding Hamiltonian reads:

$$
\boldsymbol{H}_{r}=\boldsymbol{E}_{g}-\frac{\hbar^{2}}{2 \mu} \Delta_{r}-\frac{\boldsymbol{e}^{2}}{4 \pi \varepsilon_{e f f} \boldsymbol{r}}
$$

The reduced mass is defined by $1 / \mu=1 / \boldsymbol{m}_{e}+1 / \boldsymbol{m}_{\boldsymbol{h}}$. For the relative electron-hole motion, the Hamiltonian has two types of solutions: bound pair states and a continuum of pair states having energies larger than the bandgap energy. The optical absorption reads:

$$
\begin{aligned}
& \boldsymbol{I}(\widetilde{\boldsymbol{E}}) / \boldsymbol{I}_{0}=4 \sum_{n=1}^{\infty} \frac{\gamma / \boldsymbol{n}^{3}}{\left(\widetilde{\boldsymbol{E}}+1 / \boldsymbol{n}^{2}\right)^{2}+\gamma^{2}}+\int_{0}^{\infty} \frac{\boldsymbol{d} \widetilde{\boldsymbol{E}}^{\prime}}{\boldsymbol{\pi}} \frac{\boldsymbol{\gamma} \boldsymbol{S}\left(\widetilde{\boldsymbol{E}}^{\prime}\right) \sqrt{\widetilde{\boldsymbol{E}}^{\prime}}}{\left(\widetilde{\boldsymbol{E}}-\widetilde{\boldsymbol{E}}^{\prime}\right)^{2}+\gamma^{2}} \\
& \widetilde{\boldsymbol{E}}=\frac{\hbar \boldsymbol{\omega}-\boldsymbol{E}_{g}}{\boldsymbol{R} \boldsymbol{y}} \text { is a reduced energy, } \boldsymbol{\gamma} \text { a broadening factor that depends on the temperature and } \\
& \boldsymbol{S}(\widetilde{\boldsymbol{E}})=\frac{2 \pi}{\sqrt{\widetilde{E}}\left(1-\boldsymbol{e}^{-2 \pi / \sqrt{\widetilde{E}}}\right)} \text { the absorption enhancement factor of the continuum of pair states. }
\end{aligned}
$$

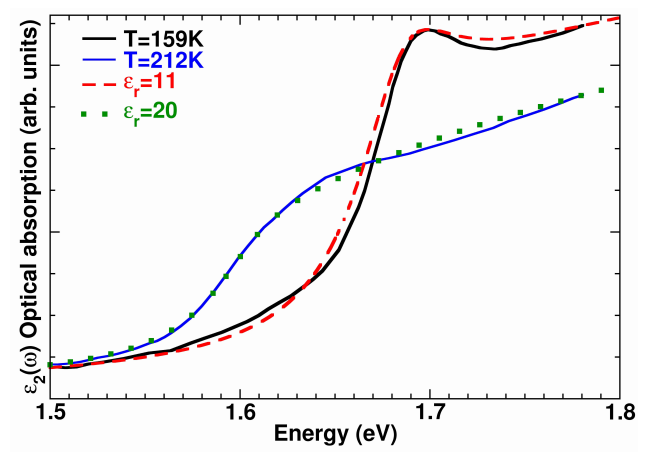

Figure 12. Optical absorption spectra of $\mathrm{CH}_{3} \mathrm{NH}_{3} \mathrm{PbI}_{3}$ highlighting exciton screening. Experimental data taken from Ref. 4 recorded at $159 \mathrm{~K}$ (black line) and $212 \mathrm{~K}$ (blue line) and computed spectra for bound and continuum pair states, considering two-particle wave function and effective mass equations for electron and hole. The effect of dielectric screening is shown for $\varepsilon_{\mathrm{eff}}=11$ (red dash line) and 20 (green dot line) and leads to a good fit of the experimental 


\section{J.Phys. Chem.C, 2015, 119 (19), pp 10161-10177 DOI: 10.1021/acs.jpcc.5b00695}

spectra below (159K) and above Tc (212K), respectively. Reprinted with permission from ref 75 . Copyright 2014 American Chemical Society.

In the limit of free carriers or a totally screened interaction, the first sum (bound exciton pair states) disappears in the optical absorption expression and $\boldsymbol{S}(\widetilde{\boldsymbol{E}})$ reduces to 1 . Simulated optical absorption spectra using this expression are compared to experimental data in Figure 12 considering different dielectric constants to highlight screening effects. Experimental absorption spectra above $\mathrm{T}_{\mathrm{c}}$ are well reproduced with a larger effective dielectric constant than below $\mathrm{T}_{\mathrm{c}}$. It yields a reduction of the $1 \mathrm{~S}$ exciton binding energy for all the spectra above $\mathrm{T}_{\mathrm{c}}$, from $\mathrm{ca} 15$ to $5 \mathrm{meV} .{ }^{75}$ The value of the exciton binding energy being smaller than $\mathrm{kT}(\sim 26 \mathrm{meV})$ at room temperature, we may infer that most electron-hole pairs are ionized yielding free carriers. This also leads to $\mathrm{ca} 80 \mathrm{meV}$ shift of the electronic bandgap at $\mathrm{T}_{\mathrm{c}}$. For $\mathrm{CH}_{3} \mathrm{NH}_{3} \mathrm{PbX}_{3}$, we thus concluded that the exciton resonance below $\mathrm{T}_{\mathrm{c}}$ is related to a Wannier like exciton already partially screened by polar modes, that becomes completely screened above Tc, yielding almost free carriers when the orientational motions of the cations are collectively activated by a structural phase transition. It shall be pointed that recent experimental results,${ }^{53}$ similar to the one reported in Figure 12 and carefully measured up to the room temperature, were discussed on the basis of a commonly accepted larger exciton binding energy $(\sim 37-50 \mathrm{meV})$ reported earlier at helium temperature. ${ }^{4,130}$ In order to overcome this apparent paradox, a complete experimental study was performed on a single crystal from helium temperature up to the room temperature (Figure 13, left part). ${ }^{131}$ In the $[25-75 \mathrm{~K}]$ temperature range, multiple exciton lines were indeed observed. The helium temperature exciton line was attributed to a bound exciton with a long lifetime, possibly arising from a strong coupling with the organic cations.

The Wannier exciton screening phenomenon was connected with a renormalization of the dielectric constant at high temperature above $\mathrm{T}_{\mathrm{c}}$ (Figure 13 , right part). ${ }^{75}$ The high frequency 


\section{J.Phys. Chem.C, 2015, 119 (19), pp 10161-10177 DOI: 10.1021/acs.jpcc.5b00695}

dielectric constant $\varepsilon_{\infty}$ is equal to about 6.5 for $\mathrm{CH}_{3} \mathrm{NH}_{3} \mathrm{PbI}_{3}$, it has a smooth variation $(\sim 30)$ as a function of the temperature in the medium frequency range $(\sim 90 \mathrm{GHz}) .{ }^{124}$ The difference between these two values can be associated to the contributions of polar optical phonons by comparison to purely inorganic $3 \mathrm{D}$ perovskites. ${ }^{75}$ The low frequency value $(\sim 1 \mathrm{KHz})$ undergoes a steep increase above the critical temperature $\mathrm{T}_{\mathrm{c},}{ }^{132}$ and amounts to about 60 at room temperature. This is attributed to the thermal activation of the collective tumblings of methyl ammonium cations ${ }^{75}$ More recently, a giant dielectric constant phenomenon was shown in these materials consisting on a low frequency dielectric constant in the dark of the order $1000{ }^{133}$ With illumination under 1 sun, an additional factor of 1000 was measured. This effect was attributed to very slowly moving photoinduced carriers assisted by molecular rotations.

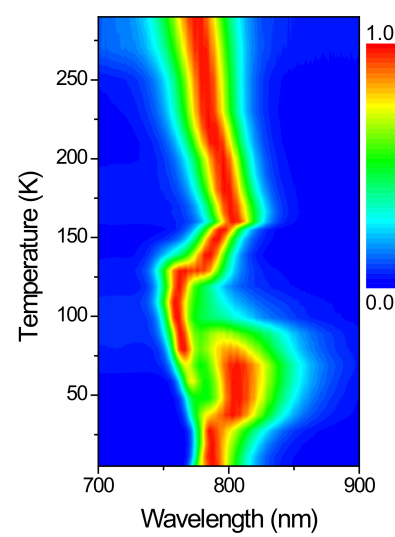

a)

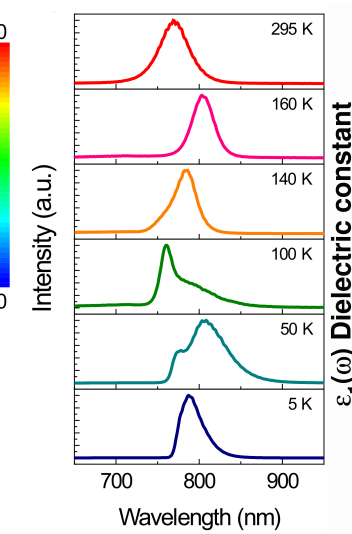

b)

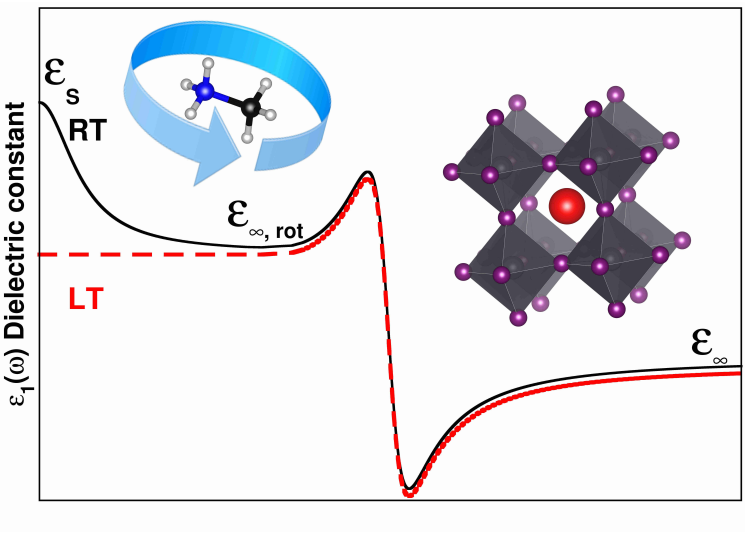

c)

Figure 13. (Left) Temperature dependent $\mathrm{PL}$ of $\mathrm{CH}_{3} \mathrm{NH}_{3} \mathrm{PbI}_{3}$ single crystal. (a) Contour plot of PL spectra of $\mathrm{CH}_{3} \mathrm{NH}_{3} \mathrm{PbI}_{3}$ single crystal at different temperatures under weak excitation density $(0.42 \mu \mathrm{J} / \mathrm{cm} 2)$ and (b) PL spectra at different temperatures. Reprinted with permission from ref 131. Copyright 2015 John Wiley and Sons. (Right, c) Schematic drawing of the dielectric constant as a function of frequency displaying respective contributions of $\mathrm{CH}_{3} \mathrm{NH}_{3}{ }^{+}$rotations and perovskite's vibrational phonons. Frequency dependence of the dielectric constant of $\mathrm{CH}_{3} \mathrm{NH}_{3} \mathrm{PbX}_{3}$ as derived from available experimental data. The high frequency response is related to vibrational polar phonons stemming from modes of the perovskite lattice (right-hand side). The low frequency region (left-hand side) shows significant differences for the low (LT, red dash line) and room (RT, black line) temperature phases. The static dielectric constant $\left(\varepsilon_{\mathrm{S}}\right)$ increase at RT is primarily attributed to rotational motion of $\mathrm{CH}_{3} \mathrm{NH}_{3}{ }^{+}$cations. Reprinted with permission from ref 75. Copyright 2014 American Chemical Society. 
For layered HOP, resonance energies of Wannier-series excitons have been measured and empirically predicted up to the $4 \mathrm{~s}$ state. ${ }^{134}$ Figure 14 -a shows the low temperature absorption spectrum of the layered $\mathrm{HOP}\left(\mathrm{C}_{6} \mathrm{H}_{5} \mathrm{C}_{2} \mathrm{H}_{4}-\mathrm{NH}_{3}\right)_{2} \mathrm{PbI}_{4}$ (PEPI) layer. The peak located at about 2.35-2.40eV correspond to the exitonic resonance, and the band to band absorption edge is located at about $2.60 \mathrm{eV}$. The exciton binding energy is thus very large on the order of 200$250 \mathrm{meV}$. For that reason, clear exciton signatures can be observed at room temperature by photoluminescence or absorption on the same compound (Figure 14-b). ${ }^{135}$ This behavior is clearly different from the one of 3D HOP (Figures 12 and 13).

In 2D HOP, the enhanced exciton binding is related to dielectric confinement and image-charge effects, where the dielectric mismatch between both the inorganic and the organic layers is the most important parameter. ${ }^{126,127}$ The 2D Wannier exciton model leads to a consistent picture where the in-plane exciton Bohr radius exceeds by far the thickness of the inorganic layer where it is confined. It allows a consistent theoretical analysis of the influence of halogen alloying on the excitonic properties of layered HOP exactly like in $\mathrm{Ga}_{1-\mathrm{x}} \mathrm{Al}_{\mathrm{x}} \mathrm{As}, \mathrm{Cd}_{1-\mathrm{x}} \mathrm{Hg}_{\mathrm{x}} \mathrm{Te}$ conventional semiconductor pseudobinary alloys. ${ }^{79}$ Figure $14-\mathrm{b}$ shows the room temperature optical tunability and inhomogeneous broadening of $\left.\mathrm{C}_{6} \mathrm{H}_{5} \mathrm{C}_{2} \mathrm{H}_{4}-\mathrm{NH}_{3}\right)_{2} \mathrm{PbI}_{4(1-\mathrm{x})} \mathrm{Br}_{4 \mathrm{x}}(\mathrm{PEPI} / \mathrm{PEPB})$ alloys.
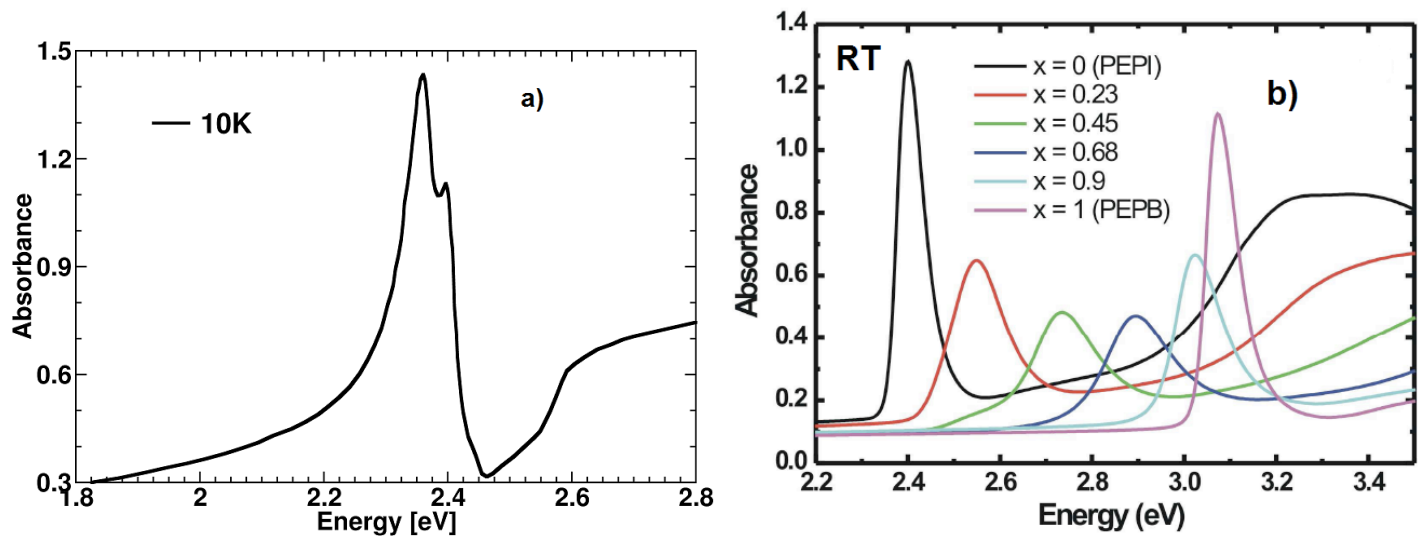

Figure 14. (a) Absorbance spectrum of a $50 \mathrm{~nm}$ thick $\left(\mathrm{C}_{6} \mathrm{H}_{5} \mathrm{C}_{2} \mathrm{H}_{4}-\mathrm{NH}_{3}\right)_{2} \mathrm{PbI}_{4}$ (PEPI) layer deposited by spin-coating on a glass substrate at $\mathrm{T}=10 \mathrm{~K}$. The peak located at about $2.35-2.40 \mathrm{eV}$ correspond to the exitonic resonance, and the band to band absorption edge is located at about 
$2.60 \mathrm{eV}$. (b) Room temperature (RT) optical absorbance spectra of $\left(\mathrm{C}_{6} \mathrm{H}_{5} \mathrm{C}_{2} \mathrm{H}_{4}-\mathrm{NH}_{3}\right)_{2} \mathrm{PbI}_{4(1-\mathrm{x})} \mathrm{Br}_{4 \mathrm{x}}$ (PEPI/PEPB) alloys. Reprinted with permission from ref 79. Copyright 2014 American Chemical Society.

Until recently, empirical modeling of dielectric confinement in layered HOP relied on crude models with ad-hoc abrupt interfaces. Recently, we have introduced the basic concepts needed to model dielectric confinement beyond an abrupt interface, based on the atomic structure of the interface. ${ }^{136}$ It solves the well-known problem of self-energy divergence at abrupt dielectric interfaces and was first implemented for CdSe colloidal nanoscale platelets. ${ }^{136}$ This method allows to bridge the gap between empirical and DFT approaches used to investigate hybrid nanoobjects with $2 \mathrm{D}$ electronic properties. ${ }^{137}$ It may also contribute to further unravel electronic and dielectric properties of HOP, especially of layered structures such as $\left(\mathrm{R}-\mathrm{NH}_{3}\right)_{2} \mathrm{MX}_{4}$ and nanocrystals or slabs of $\left(\mathrm{R}-\mathrm{NH}_{3}\right) \mathrm{MX}_{3}$.

\section{AUGER EFFECTS IN 3D HYBRID PEROVSKITES}

Next, in order to gauge the importance of third-order non-radiative Auger effects on the recombination in hybrid perovskites, let us recall a few basic properties of these effects in the case of free carriers for III-V semiconductors (Fig. 15a). An electron in the CB may recombine with a heavy hole $(\mathrm{HH})$ in the $\mathrm{VB}$, either by transferring energy and momenta to an electronic transition in the $\mathrm{CB}(\mathrm{CCCH}$ or $\mathrm{CHCC}$ process) or to a hole jumping from the $\mathrm{HH}$ band to the spin-orbit split-off (SO) band (CHHS or CHSH process). Among the numerous other possible processes, a third process (CHLH or CHHL) not represented here is usually considered in addition. This is weaker than the CHHS process, except when the spin-orbit splitting energy is larger than the band gap value. A complete computation involves repeated summations over the particle momenta and a careful description of the electronic band structure since electronic states 
away from the band gap are involved. The dependence on the electronic band gap, effective masses and carrier densities can be estimated using parabolic approximations for the electronic dispersions: ${ }^{138-140}$

$$
\begin{gathered}
\boldsymbol{R}_{\text {Auger }, C C C H} \propto \boldsymbol{n}^{2} p e^{-\left(E_{T}-E_{g a p}\right) / k T} \\
\boldsymbol{R}_{\text {Auger }, C H H S} \propto \boldsymbol{n} \boldsymbol{p}^{2} \boldsymbol{e}^{-\left(E_{T}-E_{g a p}\right) / k T}
\end{gathered}
$$

Where

$$
\begin{aligned}
& E_{T, C C C H}=\frac{2 m_{C}+m_{H H}}{m_{C}+m_{H H}} E_{g a p} \\
& E_{T, C H H S}=\frac{2 m_{H H}+m_{C}}{2 m_{H H}+m_{C}-m_{S o}}\left(E_{g a p}-\Delta\right)
\end{aligned}
$$

The Auger effect decreases exponentially as the band gap increases in III-V semiconductors. Moreover, the CHHS process prevails in most cases, when the SOC is of the same order as the band gap value. However, in n-type III-V semiconductors, the $\mathrm{CCCH}$ process is dominant through the $\boldsymbol{n}^{2} \boldsymbol{p}$ term. For large band gap materials like GaAs, where Auger processes are very weak, phonon-assisted Auger processes (not described here) give the most important contribution. $^{139}$
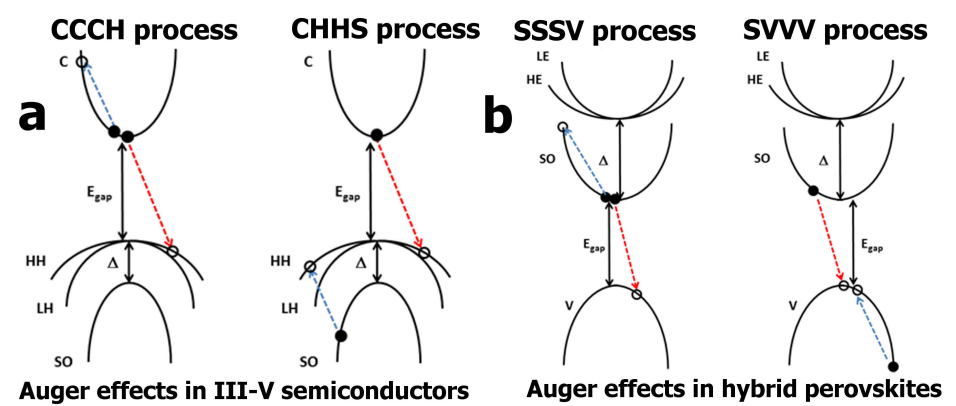

Figure 15. Dominant Auger processes in (a) III-V semiconductors and (b) hybrid perovskites. (a) HH, LH and SO correspond to heavy hole, light hole and hole spin-orbit split-off states of the VB in III-V semiconductors. (b) HE, LE and SO correspond to heavy electron, light electron and electron spin-orbit split-off states of the $\mathrm{CB}$ in hybrid perovskites. 
The electronic band structure of hybrid perovskites (Fig. 15b) has two important differences with respect to that of III-V semiconductors: 1) the band structure has a reverse band ordering, with SOC in the $\mathrm{CB}$, and 2) the SOC energy is much larger than that found in III-V semiconductors. Using the method developed for III-V semiconductors, we obtain the dependence on the electronic band gap, effective masses and carrier densities for the main two processes:

$$
\begin{gathered}
\boldsymbol{R}_{\text {Auger }, S S S V} \propto \boldsymbol{n}^{2} \boldsymbol{p} \boldsymbol{e}^{-\left(E_{T}-E_{g a p}\right) / k T} \\
\boldsymbol{R}_{\text {Auger }, S V V V} \propto \boldsymbol{n} \boldsymbol{p}^{2} \boldsymbol{e}^{-\left(E_{T}-E_{g a p}\right) / k T}
\end{gathered}
$$

where

$$
\begin{aligned}
& E_{T, S S S V}=\frac{2 m_{S}+m_{V}}{m_{S}+m_{V}} E_{g a p} \\
& E_{T, S V V V}=\frac{2 m_{V}+m_{S}}{m_{S}+m_{V}} E_{g a p}
\end{aligned}
$$

An electron in the split-off state (S) of CB may recombine with a hole (V) in the VB, either by transferring energy and momenta to an electronic transition in the split-off state of the CB (SSSV process) or to a hole in the valence band (SVVV process). Using effective masses of 0.12 and 0.15 for the split-off $\mathrm{CB}$ and for the VB respectively, we deduce that the SVVV process slightly dominates over the SSSV process, especially when considering the natural p-doping of hybrid perovskites. However, in HOP the overall effect is expected to be small like in large band gap III-V semiconductors $(\mathrm{GaAs}, \mathrm{InP}, \ldots)$. A process involving SOC, and heavy electrons (HE) or light electrons (LE) in the CB (HSSV or LSSV processes), requires a more detailed analysis, since HE and LE electronic states, lying at high energy in the CB, are hybridized with molecular states. $^{66}$

Besides, one may also expect that some of the carriers generated by the secondary optical transitions at $\mathrm{R}$ may be trapped in the $\mathrm{F}_{3 / 2 \mathrm{u}}(\mathrm{CB})$ and $\mathrm{F}_{3 / 2 \mathrm{~g}}(\mathrm{VB})$ states (Figure 4). Further 
J. Phys. Chem. C, 2015, 119 (19), pp 10161-10177 DOI: 10.1021/acs.jpcc.5b00695

relaxation $\mathrm{F}_{3 / 2 \mathrm{~g}} \rightarrow \mathrm{E}_{1 / 2 \mathrm{~g}}$ (holes) and $\mathrm{F}_{3 / 2 \mathrm{u}} \rightarrow \mathrm{E}_{1 / 2 \mathrm{u}}$ (electrons) may occur by optical phonon assisted relaxations, provided that the energy conservation rule is fulfilled. Such a "phonon bottleneck" is well-known in the case of carrier injection in semiconductor quantum dots. However, in quantum dots, carrier assisted (Auger relaxation) is the dominant effect in the high injection regime, yielding very fast carrier relaxation. A similar hot hole cooling (intraband process) from $\mathrm{F}_{3 / 2 \mathrm{~g}}$ to $\mathrm{E}_{1 / 2 \mathrm{~g}}$ is consistent with the relaxation after optical excitation reported for $\mathrm{CH}_{3} \mathrm{NH}_{3} \mathrm{PbI}_{3}{ }^{28}$

\section{COMPUTATIONAL METHODS}

Some calculations were performed using the DFT implementation available in the ABINIT package ${ }^{141}$ with the LDA or the GGA PBE gradient correction for exchange-correlation ${ }^{142}$ and relativistic, norm-conserving, separable, dual-space Gaussian type pseudopotentials of Goedecker, Teter, and Hutter for all atoms. ${ }^{143}$ The SIESTA code was used for the other simulations at the DFT-GGA level, ${ }^{144}$ calculations being performed with and without SOC. ${ }^{145}$

\section{CONCLUSIONS AND PERSPECTIVES}

In summary, this paper reviews some of the recent theoretical investigations that have contributed to gain better physical understanding of 2D and 3D HOP materials. It turns out that solid-state physics concepts are adapted to this "new" class of semiconductors, and prove to provide valuable tools when combined with DFT simulations of the optoelectronic properties. The pseudocubic perovskite structure plays a central role in this approach, allowing to define reference Bloch states and k.p Hamiltonians close to the electronic band gap. Lattice distortions, including loss of inversion symmetry, as well as spin-orbit coupling have a strong impact on the electronic band structure, in particular regarding folding, degeneracy, effective masses and optical absorption. A careful examination of the concepts of Bloch function and envelope 


\section{J. Phys. Chem.C, 2015, 119 (19), pp 10161-10177 DOI: 10.1021/acs.jpcc.5b00695}

function is particularly helpful to understand the difference between layered $\mathrm{HOP}$, and heterostructures made of 3D HOP. Carrier confinement potentials can be defined in both cases. Many-body interactions are discussed starting with excitonic interactions, where screening and dielectric confinements are of outmost importance for the optical properties at room temperature in 3D and layered HOP, respectively. The Wannier exciton picture holds for HOP in the medium to high temperature range (typically $[100-300 \mathrm{~K}]$ ). The Wannier exciton wavefunction is mostly built from the Bloch wave electronic states located on the inorganic lattice. By contrast to layered HOP, the Wannier exciton in 3D HOP is strongly screened by collective molecular rotations as well as vibrations of the inorganic lattice. This mechanism, which leads to almost free carriers at room temperature, is essential to explain the good transport properties of these materials for photovoltaic applications. In the low temperature range, the interaction of the electron-hole pairs with neighboring molecules is expected to yield bound excitons with long lifetime in 3D HOP as shown by recent experimental studies. ${ }^{131}$ Further investigations are needed to explain the microscopic origin of this strong coupling mechanism, which might be connected to the giant dielectric constant observed in 3D $\mathrm{HOP}$ at low frequency and under illumination. ${ }^{133}$ Theoretical studies on many-body effects in HOP are scarce due to the complexity of these materials. However, we have shown that semi-empirical approaches previously developed for conventional semiconductors may provide with new perspectives to analyze these effects. As an example, the detrimental non-radiative Auger effect close to the electronic band gap of 3D hybrid perovskites, is expected to have a moderate influence on the performances of optoelectronic devices. Finally, we hope to have convinced the reader that theoretical methods developed for both molecular materials and inorganic semiconductors may be efficiently combined to make further progress in the understanding of HOP. 


\section{Corresponding Author}

*Email: Jacky.Even@insa-rennes.fr

\section{Notes}

The authors declare no competing financial interests.

\section{Acknowledgments}

This work was performed using HPC resources from GENCI-CINES/IDRIS grant 2014c2012096724. The work is supported by Agence Nationale pour la Recherche (PEROCAI project ANR-10-04) and Cellule Energie du CNRS (SOLHYBTRANS Project).

\section{REFERENCES}

(1) Ishihara, T.; Takahashi, J.; Goto, T. Optical properties due to electronic transitions in twodimensional semiconductors $\left(\mathrm{C}_{\mathrm{n}} \mathrm{H}_{2 \mathrm{n}+1} \mathrm{NH}_{3}\right)_{2} \mathrm{PbI}_{4}$. Phys. Rev. B, 1990, 42, 11099-11107.

(2) Calabrese, J.; Jones, N.L.; Harlow, R.L.; Herron, N.; Thorn, D.L.; Wang, Y. Preparation and characterization of layered lead halide compounds, J. Am. Chem. Soc., 1991, 113, 2328-2330.

(3) Papavassiliou, G. C.; Patsis, A. P.; Lagouvardos, D. J.; Koutselas, I. B.; Spectroscopic studies of $\left(\mathrm{C}_{10} \mathrm{H}_{21} \mathrm{NH}_{3}\right)_{2} \mathrm{PbI}_{4},\left(\mathrm{CH}_{3} \mathrm{NH}_{3}\right)\left(\mathrm{C}_{10} \mathrm{H}_{21} \mathrm{NH}_{3}\right)_{2} \mathrm{~Pb}_{2} \mathrm{I}_{7},\left(\mathrm{CH}_{3} \mathrm{NH}_{3}\right) \mathrm{PbI}_{3}$, and similar compounds. Synthetic Metals 1993, 57, 3889.

(4) Ishihara, T. Optical properties of PbI-based perovskite structures. Journal of Luminescence, 1994, $60 \& 61,269-274$.

(5) Mitzi, D. B.; Wang, S.; Feild, C. A.; Chess, C. A.; Guloy, A. M.; Conducting layered organicinorganic halides containing < 110>-oriented perovskite sheets. Science 1995, 267, 1473.

(6) Papavassiliou, G.C.; Koutselas, I.B. Structural, optical and related properties of some natural 3dimensional and lower-dimensional semiconductor systems. Synthetic Metals, 1995, 71, 1713.

(7) Papavassiliou, G.C.; Mousdis, G.A.; Koutselas, I.B. Some new organic-inorganic hybrid semiconductors based on metal halide units: structural, optical and related properties. Adv. Mater. Opt. Electron., 1999, 9, 265-271.

(8) Hattori, T.; Taira, T.; Era, M.; Tsuitsui, T.; Saito, S. Highly efficient electroluminescence from a heterostructure device combined with emissive layered perovskite and an electron-transporting organic compound. Chem. Phys. Lett., 1996, 254, 103-108.

(9) Gebauer, T.; Schmidt, G.Z. Inorganic-organic hybrid structures LED's. Zeitschrift für Anorgnische And Allgemeine Chemie, 1999, 625, 1124-1128. 


\section{J.Phys. Chem. C, 2015, 119 (19), pp 10161-10177 DOI: 10.1021/acs.jpcc.5b00695}

(10) Kagan, C.R.; Mitzi, D.B.; Dimitrakopoulos C.D. Organic-inorganic hybrid materials as semiconducting channels in thin-film-effect transistors. Science, 1999, 286, 945-947.

(11) Mitzi, D.B.; Chondoudris, K.; Kagan, C. Organic-inorganic electronics. IBM J. Res. Dev., 2001, $45,29-45$.

(12) Mitzi, D.B.; Dimitrakopoulos, C. D.; Kosbar, L. L.; Structurally Tailored Organic-Inorganic Perovskites: Optical Properties and Solution-Processed Channel Materials for Thin-Film Transistors. Chem. Mater. 2001, 13, 3728-3740.

(13) Goto, T.; Ohshima, N.; Mousdis, G.A.; Papavassiliou, G.C. Excitons in a single two dimensional semiconductor crystal of $\mathrm{H}_{3} \mathrm{~N}\left(\mathrm{CH}_{2}\right)_{6} \mathrm{NH}_{3} \mathrm{PbI}_{4}$. Solid State Commun. 2001, 117, 13-16.

(14) Bréhier, A.; Parashkov, R.; Lauret, J.-S.; Deleporte, E. Strong exciton-photon coupling in a microcavity containing layered perovskite semiconductor. Appl. Phys. Lett. 2006, 89, 171110-171112.

(15) Wenus, J.; Parashkov, R.; Ceccarelli, S.; Bréhier, A.; Lauret, J.-S.; Skolnick, M.S.; Deleporte, E.; Lidzey, D.G. Hybrid organic-inorganic exciton-polaritons in a strongly coupled microcavity. Phys. Rev. $B, 2006,74,235212-235217$.

(16) Kojima, A.; Teshima, K.; Shirai, Y.; Miyasaka T. Organometal halide perovskites as visible-light sensitizers for photovoltaic cells. J. Am. Chem. Soc. 2009, 131, 6050-6051.

(17) Im, J.-H.; Lee, C.-R.; Lee, J.-W.; Park, S.-W.; Park, N.-G. 6.5\% Efficient Perovskite QuantumDot-Sensitized Solar Cell. Nanoscale 2011, 3, 4088-4093.

(18) Lee, M. M.; Teuscher, J.; Miyasaka, T.; Murakami, T. N.; Snaith, H. J. Efficient hybrid solar cells based on meso-superstructured organometal halide perovskites. Science. 2012, 338, 643-647.

(19) Kim, H-S.; Lee, C. R.; Im, J. H.; Lee, K. B.; Moehl, T.; Marchioro, A.; Moon, S. J.; HumphryBaker, R.; Yum, J. H.; Moser, J. E.; Grätzel, M.; Park, N. G.. Lead iodide perovskite sensitized all-solidstate submicron thin film mesoscopic solar cell with efficiency exceeding. 9\%. Sci.Rep. 2012, 2, 591-1591-7.

(20) Etgar, L.; Gao, P.; Xue, Z.; Peng, Q.; Chandiran, A. K.; Liu, B.; Nazeeruddin, M. K.; Gräzel, M. Mesoscopic $\mathrm{CH}_{3} \mathrm{NH}_{3} \mathrm{PbI}_{3} / \mathrm{TiO}_{2}$ Heterojunction Solar Cells. J. Am. Chem. Soc. 2012, 134, 17396-17399.

(21) Heo, J. H.; Im, S. H.; Noh, J. H.; Mandal, T. N.; Lim, C. S.; Chang, J. A.; Lee, Y. H.; Kim, H. J.; Sarkar, A.; Nazeeruddin, Md. K.; Grätzel, M.; Seok, S. II. Efficient inorganic-organic hybrid heterojunction solar cells containing perovskite compound and polymeric hole conductors. Nature Photonics. 2013, 7, 486-491.

(22) Burschka, J; Pellet, N.; Moon, S. J.; Humphry-Baker, R.; Gao, P.; Nazeeruddin, M. K.; Grätzel, M.. Sequential deposition as a route to high-performance perovskite-sensitized solar cells. Nature 2013, 499, 316-319.

(23) Liu, M.; Johnston, M. B.; Snaith, H. J. Efficient planar heterojunction perovskite solar cells by vapour deposition. Nature 2013, 501, 395-398.

(24) Kim, H.-S; Mora-Sero, I.; Gonzalez-Pedro, V.; Fabregat-Santiago, F.; Juarez-Perez, E. J.; Park, N. G.; Bisquert, J. Mechanism of carrier accumulation in perovskite thin-absorber solar cells. Nature Commun. 2013, 4, 2242.

(25) Noh, J. H.; Im, S. H.; Heo, J. H.; Mandal, T. N.; Seok, S. I. Chemical management for colorful, efficient, and stable inorganic-organic hybrid nanostructured solar cells. Nano Lett. 2013, 13, 1764-1769.

(26) Cai, B.; Xing, Y.; Yang, Z.; Zhang, W.-H.; Qiu, J. High Performance Hybrid Solar Cells Sensitized by Organolead Halide Perovskites. Energy Environ. Sci. 2013, 6, 1480-1485.

(27) Stranks, S. D.; Eperon, G. E.; Grancini, G.; Menelaou, C.; Alcocer, M. J. P.; Leijtens, T.; Herz, L. M.; Petrozza, A.; Snaith, H. J. Electron-hole diffusion lengths exceeding 1 micrometer in an organometal trihalide perovskite absorber. Science. 2013, 342, 341-344.

(28) Xing, G; Mathews, N.; Sun, S.; Lim, S. S.; Lam, Y. M.; Grätzel, M.; Mhaisalkar, S.; Sum, T. C. Long-range balanced electron- and hole-transport lengths in organic-inorganic $\mathrm{CH}_{3} \mathrm{NH}_{3} \mathrm{PbI}_{3}$. Science .

2013, 342, 344-347. 


\section{J.Phys. Chem.C, 2015, 119 (19), pp 10161-10177 DOI: 10.1021/acs.jpcc.5b00695}

(29) Stoumpos, C. C.; Malliakas, C. D.; Kanatzidis, M. G. Semiconducting tin and lead iodide perovskites with organic cations: Phase transitions, high mobilities, and near-infrared photoluminescent properties. Inorg. Chem. 2013, 52, 9019-9038.

(30) Laban, W. A.; Etgar, L. Depleted Hole Conductor-Free Lead Halide Iodide Heterojunction Solar Cells. Energy Environ. Sci. 2013, 6, 3249-3253.

(31) Dualeh, A.; Moehl, T.; Tétreault, N.; Teuscher, J.; Gao, P.; Nazeeruddin, M. K.; Grätzel, M. Impedance Spectroscopic Analysis of Lead Iodide Perovskite-Sensitized Solid-State Solar Cells. ACS Nano 2013, 8, 362-373.

(32) Leijtens, T.; Eperon, G. E.; Pathak, S.; Abate, A.; Lee, M. M.; Snaith, H. J. Overcoming Ultraviolet Light Instability of Sensitized TiO2 with Meso-Superstructured Organometal Tri-Halide Perovskite Solar Cells. Nat. Commun. 2013, 4, 2885.

(33) Park, N. G. Organometal perovskite light absorbers toward a 20\% efficiency low-cost solid-state mesoscopic solar cell. J. Phys Chem. Lett. 2013, 4, 2423-2429.

(34) Snaith, H. J. Perovskites: The emergence of a new era for low-cost, high-efficiency solar cells. $J$. Phys Chem. Lett. 2013, 4, 3623-3630.

(35) Kim, H.S.; Im, S. H.; Park, N.-G. Organolead Halide Perovskite: New Horizons in Solar Cell Research. J. Phys. Chem. C 2014, 118, 5615-5625.

(36) Gao, P.; Graëtzel, M.; Nazeeruddin, M. K. Organohalide lead perovskites for photovoltaic applications. Energy Environ. Sci. 2014, 7, 2448-2463.

(37) Sum, T. C.; Mathews, N. Advancements in perovskite solar cells: photophysics behind the photovoltaics. Energy Environ. Sci. 2014, 7, 2518-2534.

(38) Green, M. A.; Ho-Baillie, A; Snaith, H. J. The emergence of perovskite solar cells. Nature Photonics 2014 8, 506-514.

(39) Zhou, H., Chen, Q., Li, G., Luo, S., Song, T.-B., Duan, H.-S., Hong, Z., You, J., Liu, Y., Yang, Y. Interface engineering of highly efficient perovskite solar cells. Science 2014 345, 542-546.

(40) Luo, J.; Im, J.-H.; Mayer, M. T.; Schreier, M.; Nazeeruddin, M. H.; Park, N.-G.; Tilley, S. D.; Fan, H. J.; Grätzel, M.; Water photolysis at $12.3 \%$ efficiency via perovskite photovoltaics and Earthabundant catalysts. Science 2014 345, 1593-1596.

(41) Hao, F.; Stoumpos, C. C.; Cao, D. H.; Chang, R. P. H.; Kanatzidis, M. G. Lead-free solid-state organic-inorganic halide perovskite solar cells. Nature Photonics 2014 8, 489-494.

(42) Ogomi, Y.; Morita, A.; Tsukamoto, S.; Saitho, T.; Fujikawa, N.; Shen, Q.; Toyoda, T.; Yoshino,

K.; Pandey, S. S.; Ma, T.; Hayase, S.; $\mathrm{CH}_{3} \mathrm{NH}_{3} \mathrm{Sn}_{\mathrm{x}} \mathrm{Pb}_{(1-\mathrm{x})} \mathrm{I}_{3}$ Perovskite Solar Cells Covering up to $1060 \mathrm{~nm}$. J. Phys. Chem. Lett. 2014, 5, 1004-1011.

(43) Noel, N. K.; Stranks, S. D.; Abate, A.; Wehrenfennig, C.; Guarnera, S.; Haghighirad, A.; Sadhanala, A.; Eperon, G. E.; Pathak, S. K.; Johnston, M. B.; petrozza, a.; Herz, L.; Snaith, H. Energy Environ. Sci. 2014, 7, 3061-3068.

(44) Gonzalez-Pedro, V.; Juarez-Perez, E. J.; Arsyad, W.-S.; Barea, E. M.; Fabregat-Santiago, F.; Mora-Sero, I.; Bisquert, J. General Working Principles of $\mathrm{CH}_{3} \mathrm{NH}_{3} \mathrm{PbX}_{3}$ Perovskite Solar Cells. Nano Lett. 2014, 14, 888-893.

(45) Kim, H. -S.; Park, N.-G.; Parameters Affecting I-V Hysteresis of $\mathrm{CH}_{3} \mathrm{NH}_{3} \mathrm{PbI}_{3}$ Perovskite Solar Cells: Effects of Perovskite Crystal Size and Mesoporous TiO2 Layer. J. Phys. Chem. Lett. 2014, 5, $2927-$ 2934.

(46) Sánchez, R. S.; Gonzalez-Pedro, V.; Lee, J.-W.; Park, N.-G.; Kang, Y. S.; Mora-Sero, I.; Bisquert, J. Slow Dynamic Processes in Lead Halide Perovskite Solar Cells. Characteristic Times and Hysteresis. J. Phys. Chem. Lett. 2014, 5, 2357-2363.

(47) Wehrenfennig, C.; Liu, M.; Snaith, H. J.; Johnston, M. B.; Herz, L. M. Homogeneous Emission Line Broadening in the Organo Lead Halide Perovskite $\mathrm{CH}_{3} \mathrm{NH}_{3} \mathrm{PbI}_{3-\mathrm{x}} \mathrm{Cl}_{\mathrm{x}}$. J. Phys. Chem. Lett. 2014, 5 , 1300-1306.

(48) Deschler, F.; Price, M.; Pathak, S.; Klintberg, L. E.; Jarausch, D. -D.; Higler, R.; Hüttner, S.; Leijtens, T.; Stranks, S. D.; Snaith, H. J.; Atatüre, M.; Phillips, R. T.; Friend, R. H.; High 


\section{J. Phys. Chem.C, 2015, 119 (19), pp 10161-10177 DOI: 10.1021/acs.jpcc.5b00695}

Photoluminescence Efficiency and Optically Pumped Lasing in Solution-Processed Mixed Halide Perovskite Semiconductors. J. Phys. Chem. Lett. 2014, 5, 1421-1426.

(49) Xing, G.; Mathews, N.; Lim, S. M.; Yantara, N.; Liu, X.; Sabba, D.; Grätzel, M.; Mhaisalkar, S.; Sum, T. C. Low-temperature solution-processed wavelength-tunable perovskites for lasing. Nature Mat. 2014, 13, 476-480.

(50) Tan, Z.K.; Moghaddam, R.S.; Lai, M.L.; Docampo, P.; Higler, R.; Deschler, F.; Price, M.; Sadhanala, A.; Pazos, L.M.; Credgington, D.; Hanusch, F.; Bein, T.; Snaith, H.J.; Friend, R.H. Bright light-emitting diodes based on organometal halide perovskite. Nature Nanotech., 2014 , 9, 687-692.

(51) Stranks, S. D.; Burlakov, V. M.; Leijtens,T.; Ball, J. M; Goriely, A.; Snaith,H.J. Recombination Kinetics in Organic-Inorganic Perovskites: Excitons, Free Charge, and Subgap States. Phys. Rev. Appl. 2014, 2, 034007.

(52) Yamada, Y., Nakamura, T., Endo, M., Wakamiya, A.,and Kanemitsu, Y., Photocarrier Recombination Dynamics in Perovskite $\mathrm{CH}_{3} \mathrm{NH}_{3} \mathrm{PbI}_{3}$ for Solar Cell Applications. J. Am. Chem. Soc . 2014, 136, 11610-11613.

(53) D'Innocenzo, V., Grancini, G., Alcocer, M. J. P., Ram Srimath Kandada, A., Stranks, S. D., Lee, M. M., Lanzani, G., Snaith, H. J., Petrozza, A. Excitons versus free charges in organo-lead-tri-halide perovskites. Nat. Commun. 2014, 5:3586 doi: 10.1038/ncomms4586.

(54) Savenije, T. J.; Ponseca Jr., C. S.; Kunneman, L.; Abdellah, M.; Zheng, K.; Tian, Y.; Zhu, Q.; Canton, S. E.; Scheblykin, I. G.; Pullerits, T.; Yartsev, A.; Sundström, V.; Thermally Activated Exciton Dissociation and Recombination Control the Carrier Dynamics in Organometal Halide Perovskite. $J$. Phys. Chem. Lett. 2014, 5, 2189-2194.

(55) Umebayashi, T.; Asai, K.; Kondo, T.; Nakao, A.; Electronic Structures of Lead Iodide Based Low-Dimensional Crystals. Phys Rev B. 2003, 67, 155405-6.

(56) Chang, Y. H.; Park, C. H.; Matsuishi, K.; First-Principles Study of the Structural and the Electronic Properties of the Lead-Halide-Based Inorganic-Organic Perovskites $\left(\mathrm{CH}_{3} \mathrm{NH}_{3}\right) \mathrm{PbX}_{3}$ and $\mathrm{CsPbX}_{3}(\mathrm{X}=\mathrm{Cl}, \mathrm{Br}, \mathrm{I})$. J. Korean Physical Soc. 2004, 44, 889-893.

(57) Sourisseau, S.; Louvain, N. ; Bi, W. ; Mercier, N. ; Rondeau, D. ; Boucher, F. ; Buzaré, J.-Y. ; Legein, C.; Reduced Band Gap Hybrid Perovskites Resulting from Combined Hydrogen and Halogen Bonding at the Organic-Inorganic Interface. Chem. Mater. 2007 19, 600-607.

(58) Borriello, I.; Cantele, G.; Ninno, D.; Ab initio investigation of hybrid organic-inorganic perovskites based on tin halides. Phys. Rev. B 2008, 77, 235214.

(59) Chiarella, F.; Zappettini, A.; Licci, F.; Borriello, I.; Cantele, G.; Ninno, D.; Cassinese, A.; Vaglio, R.; Combined Experimental and Theoretical Investigation of Optical, Structural, And Electronic Properties of $\mathrm{CH}_{3} \mathrm{NH}_{3} \mathrm{SnX}_{3}$ Thin Films. (X=Cl,Br). Phys. Rev. B 2008, 77, 0451294.

(60) Murtaza, G.; Ahmad, I.; First Principle Study of the Structural and Optoelectronic Properties of Cubic Perovskites CsPbM3 (M=Cl, Br, I). Physica B: Condensed Matter 2011, 406, 3222-3229.

(61) Even, J.; Pedesseau, L.; Dupertuis, M.-A.; Jancu, J.-M.; Katan, C.; Electronic model for selfassembled hybrid organic/perovskite semiconductors: Reverse band edge electronic states ordering and spin-orbit coupling. Phys. Rev. B. 2012, 86, 205301.

(62) Jin, H.; Im, J.; Freeman, A. J.; Topological insulator phase in halide perovskite structures. Phys. Rev. B. 2012, 86, 121102(R).

(63) Chung, I.; Song, J.H.; Im, J.; Androulakis, J.; Malliakas, C.D.; Li, H.; Freeman, A.J.; Kenney, J.T.; Kanatzidis, M.G.; CsSnI3: Semiconductor or Metal? High Electrical Conductivity and Strong NearInfrared Photoluminescence from a Single Material. High Hole Mobility and Phase-Transitions. J. Am. Chem. Soc., 2012, 134, 8579-8587.

(64) Ayatullahah, H.; Murtaza, G.; Muhammad, S.; Naeem, S.; Khalid, M. N.; Manzar, A.; Physical Properties of CsSnM3 (M = Cl, Br, I): A First Principle Study. Acta Phys. Pol. 2013, 124, 102-107

(65) Huang, L.-Y., Lambrecht, W. R. L.; Electronic band structure, phonons, and exciton binding energies of halide perovskites $\mathrm{CsSnCl}_{3}, \mathrm{CsSnBr}_{3}$, and $\mathrm{CsSnI}_{3}$. Phys. Rev. B. 2013, 88, 165203.

(66) Even, J.; Pedesseau, L.; Jancu, J.-M.; Katan, C.; Importance of spin-orbit coupling in hybrid organic/inorganic perovskites for photovoltaic applications. J. Phys. Chem. Lett. 2013, 4, 2999-3005. 


\section{J.Phys. Chem. C, 2015, 119 (19), pp 10161-10177 DOI: 10.1021/acs.jpcc.5b00695}

(67) Colella, S.; Mosconi, E.; Fedeli, P.; Listorti, A.; Gazza, F.; Orlandi, F.; Ferro, P.; Besagni, T.; Rizzo, A.; Calestani, G.; Gigli, G.; De Angelis, F.; Mosca, R.; MAPbI ${ }_{3-x} \mathrm{Cl}_{\mathrm{x}}$ mixed halide perovskite for hybrid solar cells: The role of chloride as dopant on the transport and structural properties. Chem. Mater. 2013, 25, 4613-4618.

(68) Mosconi, E.; Amat, A.; Nazeeruddin, Md. K.; Grätzel, M.; De Angelis, F.; First-principles modeling of mixed halide organometal perovskites for photovoltaic applications. J. Phys. Chem. C 2013, 117, 13902-13913.

(69) Giorgi, V.; Fujisawa, J.-I.; Segawa, H.; Yamashita, K.; Small photocarrier effective masses featuring ambipolar transport in methylammonium lead iodide perovskite: A density functional analysis. J. Phys. Chem. Lett. 2013, 4, 4213-4216.

(70) Brivio, F.; Walker, A. B.; Walsh, A.; Structural and electronic properties of hybrid perovskites for high-efficiency thin-film photovoltaics from first-principles. Appl. Phys. Lett. Mat. 2013, 1, 042111-1042111-5.

(71) Baikie, T.; Fang, Y.; Kadro, J. M.; Schreyer, M.; Wei, F.; Mhaisalkar, S. G.; Graetzel, M.; White, T. J.; Synthesis and crystal chemistry of the hybrid perovskite $\left(\mathrm{CH}_{3} \mathrm{NH}_{3}\right) \mathrm{PbI}_{3}$ for solid-state sensitised solar cell applications. J. Mater. Chem. A. 2013, 1, 5628-5641.

(72) Wang, Y.; Gould, T.; Dobson, J. F.; Zhang, H.; Yang, H.; Yao, X.; Zhao, H.; Density Functional Theory Analysis of Structural and Electronic Properties of Orthorhombic Perovskite $\mathrm{CH}_{3} \mathrm{NH}_{3} \mathrm{PbI}_{3}$. Phys . Chem. Chem. Phys. 2013, 16, 1424-1429.

(73) Pedesseau, L.; Jancu, J-M.; Rolland, A.; Deleporte, E.; Katan, C.; Even, J. Electronic properties of 2D and 3D hybrid organic/inorganic perovskites for optoelectronic and photovoltaic applications. Opt. Quant. Electron. 2014, 46, 1225-1232

(74) Even, J.; Pedesseau, L.; Jancu, J.-M.; Katan, C. DFT and k $\bullet$ p modelling of the phase transitions of lead and tin halide perovskites for photovoltaic cells. Phys. Status Solidi RRL. 2014, 8, 31-35.

(75) Even, J.; Pedesseau, L.; Katan, C.; Analysis of Multivalley and Multibandgap Absorption and Enhancement of Free Carriers Related to Exciton Screening in Hybrid Perovskites. J. Phys. Chem. C 2014, 118, 11566-11572.

(76) Even, J.; Pedesseau, L.; Tea, E.; Almosni, S.; Rolland, A.; Robert, C.; Jancu, J.-M.; Cornet, C.; Katan, C.; Guillemoles, J.-F.; Durand, O. Int. J. Photoener. 2014, 2014, 649408.

(77) Katan, C.; Pedesseau, L.; Kepenekian, M.; Rolland, A.; Even, J.; Interplay of spin-orbit coupling and lattice distortion in metal substituted 3D tri-chloride hybrid perovskites. J. Mater. Chem. A., 2015, DOI: $10.1039 / \mathrm{c} 4 \mathrm{ta} 06418 \mathrm{f}$.

(78) Even, J.; Pedesseau, L.; Katan, C.; Theoretical insights into multibandgap hybrid perovskites for photovoltaic applications. Proc. SPIE 2014, 9140, 91400Y.

(79) Lanty, G.; Jemli, K.; Wei, Y.; Leymarie, J.; Even, J.; Lauret, J.-S.;Deleporte, E.; RoomTemperature Optical Tunability and Inhomogeneous Broadening in 2D-Layered Organic-Inorganic Perovskite Pseudobinary Alloys. J. Phys. Chem. Lett., 2014, 5, 3625-3631.

(80) Umari, P.; Mosconi, E.; De Angelis, F.; Relativistic GW calculations on $\mathrm{CH}_{3} \mathrm{NH}_{3} \mathrm{PbI}_{3}$ and $\mathrm{CH}_{3} \mathrm{NH}_{3} \mathrm{SnI}_{3}$ Perovskites for Solar Cell Applications. Sci. Rep. 2014, 4, 4467.

(81) Roiati, V.; Mosconi, E.; Listorti, A.; Colella, S.; Gigli, G.; De Angelis, F.; Stark Effect in Perovskite/ $/ \mathrm{TiO}_{2}$ Solar Cells: Evidence of Local Interfacial Order. Nano Lett. 2014, 14, 2168-2174.

(82) Mosconi, E.; De Angelis, F.; First Principles Investigation of the $\mathrm{TiO}_{2} /$ Organohalide Perovskites Interface: The Role of Interfacial Chlorine. J. Phys. Chem. Lett. 2014, 5, 2619-2625.

(83) Amat, A.; Mosconi, E.; Ronca, E.; Quarti, C.; Umari, P.; Nazeeruddin, M. K.; Grätzel, M.; De Angelis, F.; Cation-Induced Band-Gap Tuning in Organohalide Perovskites: Interplay of Spin-Orbit Coupling and Octahedra Tilting. Nano Lett. 2014, 14, 3608-3616.

(84) Quarti, C.; Grancini, G.; Mosconi, E.; Bruno, P.; Ball, J. M.; Lee, M. M.; Snaith, H. J.; Petrozza, A.; De Angelis, F.; The Raman Spectrum of the $\mathrm{CH}_{3} \mathrm{NH}_{3} \mathrm{PbI}_{3} \mathrm{Hybrid}$ Perovskite: Interplay of Theory and Experiment. J. Phys. Chem. Lett. 2014, 5, 279-284. 


\section{J. Phys. Chem. C, 2015, 119 (19), pp 10161-10177 DOI: 10.1021/acs.jpcc.5b00695}

(85) Gottesman, R.; Haltzi, E.; Gouda, L.; Tirosh, S.; Bouhadana, Y.; Zaban, A.; Mosconi, E.; De Angelis, F.; Extremely Slow Photoconductivity Response of $\mathrm{CH}_{3} \mathrm{NH}_{3} \mathrm{PbI}_{3}$ Perovskites Suggesting Structural Changes under Working Conditions. J. Phys. Chem. Lett., 2014, 5, 2662-2669.

(86) Grancini, G.; Marras, S.; Prato, M.; Giannini, C.; Quarti, C.; De Angelis, F.; De Bastiani, M.; Eperon, G. E.; Snaith, H. J.; Manna, L.; Petrozza, A.; The Impact of the Crystallization Processes on the Structural and Optical Properties of Hybrid Perovskite Films for Photovoltaics. J. Phys. Chem. Lett., 2014, 5 , 3836-3842.

(87) Quarti, C.; Mosconi, E.; De Angelis; Interplay of Orientational Order and Electronic Structure in Methylammonium Lead Iodide: Implications for Solar Cell Operation. Chem. Mater.,_DOI: $10.1021 / \mathrm{cm} 5032046$.

(88) De Angelis, F.; Modeling Materials and Processes in Hybrid/Organic Photovoltaics: From DyeSensitized to Perovskite Solar Cells. Acc. Chem. Res., DOI: 10.1021/ar500089n.

(89) Giorgi, V.; Fujisawa, J.-I.; Segawa, H.; Yamashita, K.; The Cation Role in Structural and Electronic Properties of 3D Organic-Inorganic Perovskite Halides: A DFT Analysis. J. Phys. Chem. C 2014, 118, 12176-12183.

(90) Giorgi, V.; Yamashita, K.; Organic-Inorganic halide perovskites: an ambipolar class of materials with enhanced photovoltaic performances. J. Mater. Chem. A DOI: 10.1039/C4TA05046K.

(91) Frost, J. M.; Butler, K. T.; Brivio, F.; Hendon, C. H.; van Schilfgaarde, M.; Walsh, A.; Atomistic origins of high-performance in hybrid halide perovskite solar cells. Nano Lett., 2014, 14, 2584-2590.

(92) Brivio, F.; Butler, K. T.; Walsh, A.; van Schilfgaarde, M. Relativistic quasiparticle selfconsistent electronic structure of hybrid halide perovskite photovoltaic absorbers. Phys. Rev. B 2014, 89, 155204.

(93) Butler, K. T.; Frost, J. M.; Walsh, A.; Band alignment of the hybrid halide perovskites $\mathrm{CH}_{3} \mathrm{NH}_{3} \mathrm{PbCl}_{3}, \mathrm{CH}_{3} \mathrm{NH}_{3} \mathrm{PbBr}_{3}$ and $\mathrm{CH}_{3} \mathrm{NH}_{3} \mathrm{PbI}_{3}$. Mater. Horiz. DOI: $10.1039 / \mathrm{C} 4 \mathrm{MH} 00174 \mathrm{E}$.

(94) Yin, W.-J.; Shi, T.; Yan, Y.; Unique Properties of Halide Perovskites as Possible Origins of the Superior Solar Cell Performance. Adv. Mat. 2014, 26, 4653-4658.

(95) Yin, W. J.; Yan, Y.; Wei S.-H.; Anomalous Alloy Properties in Mixed Halide Perovskites. J. Phys. Chem. Lett., 2014, 5, 3625-3631.

(96) Yin, W.-J.; Shi, T.; Yan, Y.; Unusual Defect Physics in $\mathrm{CH}_{3} \mathrm{NH}_{3} \mathrm{PbI}_{3}$ Perovskite Solar Cell Absorber. Appl. Phys. Lett. 2014, 104, 063903.

(97) Shi, T.; Yin, W. J.; Yan, Y.; Predictions for p-Type $\mathrm{CH}_{3} \mathrm{NH}_{3} \mathrm{PbI}_{3}$ Perovskites. J. Phys. Chem. C 2014, 118, 25350-25354.

(98) Kim, J. ; Lee, S.-H.; Lee, J. H.; Hong, K.-H.; The Role of Intrinsic Defects in Methylammonium Lead Iodide Perovskite. J. Phys. Chem. Lett., 2014, 5, 1312-1317.

(99) Du, M. H.; Efficient carrier transport in halide perovskites: theoretical perspectives. J. Mater. Chem. A, 2014, 9091-9098.

(100) Shi, H; Du, M. H.; Shallow halogen vacancies in halide optoelectronic materials. Phys. Rev. B, 2014, 90, 174103.

(101) Buin, A.; Pietsch, P.; Xu, J.; Voznyy, O.; Ip, A. H.; Comin, R.; Sargent, E. H.; Materials Processing Routes to Trap-Free Halide Perovskites. Nano Letters 2014 DOI: 10.1021/nl502612m.

(102) Feng, J.; Xiao, B.; Effective Masses and Electronic and Optical Properties of Nontoxic MASnX 3 $(\mathrm{X}=\mathrm{Cl}, \mathrm{Br}$, and I) Perovskite Structures as Solar Cell Absorber: A Theoretical Study Using HSE06. J.

Phys. Chem. C, 2014, 118, 19655-19660.

(103) Feng, J.; Xiao, B.; Crystal Structures, Optical Properties, and Effective Mass Tensors of $\mathrm{CH}_{3} \mathrm{NH}_{3} \mathrm{PbX}_{3}(\mathrm{X}=\mathrm{I}$ and $\mathrm{Br}$ ) Phases Predicted from HSE06. J. Phys. Chem. Lett. 2014, 5, 1278-1282.

(104) Feng, J.; Mechanical properties of hybrid organic-inorganic $\mathrm{CH}_{3} \mathrm{NH}_{3} \mathrm{BX}_{3}(\mathrm{~B}=\mathrm{Sn}, \mathrm{Pb} ; \mathrm{X}=\mathrm{Br}, \mathrm{I})$ perovskites for solar cell absorbers. APL Mat. 2014, 2, 081801

(105) Lang, L.; Yang, J.-H.; Liu, H.-R.; Xiang, H.J.; Gong, X.G.; First-principles study on the electronic and optical properties of cubic $\mathrm{ABX}_{3}$ Halide Perovskites. Phys. Lett. A 2014, 378, 290-293. (106) Filippetti, A.; Mattoni, A.; Hybrid perovskites for photovoltaics: Insights from first principles. Phys. Rev. B 2014, 89, 125203. 
(107) Filippetti, A.; Delugas, P.; Mattoni, A.; Methylammonium Lead-Iodide Perovskite: Recombination and Photoconversion of an Inorganic Semiconductor Within a Hybrid Body. J. Phys. Chem. C, 2014, 118, 24843-24853.

(108) Menéndez-Proupin, E.; Palacios, P.; Wahnón, P.; Conesa, J. C. Self-consistent relativistic band structure of the $\mathrm{CH}_{3} \mathrm{NH}_{3} \mathrm{PbI}_{3}$ perovskite. Phys. Rev. B, 2014, 90, 045207

(109) Geng, W.; Zhang, L.; Zhang, Y.-N.; Lau, W.-N.; Liu, L.M.; First-Principles Study of Lead Iodide Perovskite Tetragonal and Orthorhombic Phases for Photovoltaics. J. Phys. Chem. C, 2014, 118, 1956519571.

(110) Bernal, C.; Yang K.; First-Principles Hybrid Functional Study of the Organic-Inorganic Perovskites $\mathrm{CH}_{3} \mathrm{NH}_{3} \mathrm{SnBr}_{3}$ and $\mathrm{CH}_{3} \mathrm{NH}_{3} \mathrm{SnI}_{3}$. J. Phys. Chem. C, 2014, 118, 24383-24388.

(111) Grote, C.; Ehrlich, B.; Berger, R.F.; Tuning the near-gap electronic structure of tin-halide and lead-halide perovskites via changes in atomic layering. Phys. Rev. B 2014, 90, 205202.

(112) Egger, D. A.; Kronik; L. Role of Dispersive Interactions in Determining Structural Properties of Organic-Inorganic Halide Perovskites: Insights from First-Principles Calculations. J. Phys. Chem. Lett.

2014, 5, 2728-2733.

(113) Jishi, R. A.; Ta, O. B.; Sharif, A. A.; Modeling of Lead Halide Perovskites for Photovoltaic Applications. J. Phys. Chem. C, DOI: $10.1021 /$ jp5050145.

(114) He, Y.; Galli, G.; Perovskites for Solar Thermoelectric Applications: A First Principle Study of $\mathrm{CH}_{3} \mathrm{NH}_{3} \mathrm{AI}_{3}(\mathrm{~A}=\mathrm{Pb}$ and $\mathrm{Sn})$. Chem. Mater., 2014, 26, 5394-5400.

(115) Kim, M.; Im, J.; Freeman, A. J.; Ihm, J.; Jin, H.; Switchable S = 1/2 and J = 1/2 Rashba bands in ferroelectric halide perovskites. PNAS, 2014, 111, 6900-6904.

(116) Castelli, I. E.; García-Lastra, J. M.; Thygesen, K. S.; Jacobsen, K. W.; Bandgap calculations and trends of organometal halide perovskites. APL Mat. 2014, 2, 081514.

(117) Zhu, X.; Su, H.; Marcus, R. A.; Michel-Beyerle, M. A.; Computed and Experimental Absorption Spectra of the Perovskite $\mathrm{CH}_{3} \mathrm{NH}_{3} \mathrm{PbI}_{3}$. J. Phys. Chem. Lett., 2014, 5, 3061-3065.

(118) Lindblad, R.; Bi, D.; Park, B.-w.; Oscarsson, J.; Gorgoi, M.; Siegbahn, H.; Odelius, M.;Johansson, E. M. J.; Rensmo, H.; Electronic Structure of TiO2/CH3NH3PbI3 Perovskite Solar Cell Interfaces. J. Phys. Chem. Lett., 2014, 5, 648-653.

(119) Haruyama, J.; Sodeyama, K.; Han, L.; Tateyama, Y.; Termination Dependence of Tetragonal $\mathrm{CH}_{3} \mathrm{NH}_{3} \mathrm{PbI}_{3}$ Surfaces for Perovskite Solar Cells. J. Phys. Chem. Lett., 2014, 5, 2903-2909.

(120) Torres, A.; Rego, L. G. C.; Surface Effects and Adsorption of Methoxy Anchors on Hybrid Lead Iodide Perovskites: Insights for Spiro-MeOTAD Attachment. J. Phys. Chem. C, DOI: $10.1021 /$ jp510595s.

(121) Miller, E. M.; Zhao,Y.; Mercado, C. C.; Saha, S. K.; Luther, J. M.; Zhu, K.; Stevanovic, V.; Perkins, C. L.; van de Lagemaat, J.; Substrate-controlled band positions in $\mathrm{CH}_{3} \mathrm{NH}_{3} \mathrm{PbI}_{3}$ perovskite films. Phys. Chem.Chem. Phys., 2014, 16, 22122-22130.

(122) http://www.nrel.gov/ncpv/images/efficiency_chart.jpg (accessed Mar 18, 2015)

(123) Chuang, S. Physics of Optoelectronic Devices. (J. W. Goodman Ed., New York: Wiley, 1995).

(124) Poglitsch, A.; Weber, D. Dynamic disorder in methylammoniumtrihalogenoplumbates (II) observed by millimeter-wave spectroscopy. J. Chem. Phys., 1987, 87, 6373-6378.

(125) Winkler, R.; Spin-orbit Coupling Effects in Two-Dimensional Electron and Hole Systems. NewYork: Springer Tracts in Modern Physics. 2004 Springer-Verlag

(126) Hong, X.; Ishihara, T.; Nurmikko, A. U.; Dielectric confinement eff'ect on excitons in PbI4-based layered semiconductors. Phys. Rev. B, 1992, 45, 6961-6964.

(127) Muljarov, E. A.; Tikhodeev, S. G.; Gippius, N. A.; Ishihara, T.; Excitons in self-organized semiconductor/insulator superlattices: PbI-based perovskite compounds. Phys. Rev. B, 1995, 51, 1437014378.

(128) Even, J.; Pedesseau, L.; Katan, C. Understanding Quantum Confinement of Charge Carriers in Layered 2D Hybrid Perovskites. Chem. Phys. Chem., 2014, 15 (17), 3733-3741. 
(129) Tanaka, K.; Kondo, T.; Bandgap and exciton binding energies in lead-iodide-based natural quantum-well crystals. Sci. Technol. Adv. Mat., 2003 4, 599-604.

(130) Hirasawa, M.; Ishihara, T.; Goto, T.; Uchida, K.; Miura, N. Magnetoabsorption of the lowest exciton in perovskite-type compound $\left(\mathrm{CH}_{3} \mathrm{NH}_{3}\right) \mathrm{PbI}_{3}$. Physica B, 1994, 201, 427-430.

(131) Fang, H.-H.; Raissa, R. ; Abdu-Aguye, M.; Adjokatse, S.; Blake, G.R.; Even, J.; Loi, M. A. Photophysics of Organic-Inorganic Hybrid Lead Iodide Perovskite Single Crystals, Adv. Func. Mat., DOI: $10.1002 /$ adfm.201404421

(132) Onoda-Yamamuro, N.; Matsuo, T.; Suga, H., Dielectric study of $\mathrm{CH}_{3}, \mathrm{NH}_{3} \mathrm{PbX}_{3}(\mathrm{X}=\mathrm{Cl}, \mathrm{Br}, \mathrm{I}) . J$. Phys. Chem. Solids, 1992, 53, 935-939.

(133) Juarez-Perez, E. J.; Sanchez, R. S.; Badia, L. Garcia-Belmonte, G.; Kang, Y. S.; Mora-Sero, I; Bisquert, J.; Photoinduced Giant Dielectric Constant in Lead Halide Perovskite Solar Cells. J. Phys. Chem. Lett., 2014, 5, 2390-2394.

(134) Tanaka, K.; Takahashi, T.; Kondo, T.; Umebayashi, T.; Asai, K.; Ema, K.; Image charge effect on two-dimensional excitons in an inorganic-organic quantum-well crystal. Phys. Rev. B 2005, 71, 045312 .

(135) Zhang, S. ; Audebert, P.; Wei, Y ; Choueiry, A. A.; Lanty, G. ; Bréhier, A. ; Galmiche, L. ; Clavier, G. ; Boissière, C.; Lauret, J.-S. ; Deleporte, E.; Preparations and Characterizations of Luminescent Two Dimensional Organic-inorganic Perovskite Semiconductors Materials 2010, 3, 33853406.

(136) Even, J.; Pedesseau, L.; Kepenekian, M.; Electronic surface states and dielectric self-energy profiles in colloidal nanoscale platelets of CdSe. Phys. Chem. Chem. Phys., 2014, 16, 25182-25190.

(137) Benchamekh, R. N.; Gippius, A.; Even, J.; Nestoklon, M. O.; Jancu, J.-M.; Ithurria, S.; Dubertret, B.; Efros, A. L.; Voisin, P.; Tight-binding calculations of image-charge effects in colloidal nanoscale platelets of CdSe. Phys. Rev. B, 2014, 89, 035307.

(138) Beattie, A. R.; Landsberg, P.T.; Auger effects in semiconductors, Proc. R. Soc. Lond. A, 1959 249, 16-29.

(139) Agrawal, G. P.; Dutta, N. K.; Long-wavelength semiconductor lasers (New York: Van Nostrand Reinhold, 1986)

(140) Coldren, L.A.; Corzine, S. W.; Diode Lasers and Photonic Integrated Circuits (New York: Wiley, 1995)

(141) Gonze, X.; Amadon, B.; Anglade, P. M.; Beuken, J. M.; Bottin, F.; Boulanger, P.; Bruneval, F.; Caliste, D.; Caracas, R.; Cote, M.; et al. ABINIT: First-Principles Approach to Material and Nanosystem Properties. Comput. Phys. Commun., 2009, 180 (12), 2582-2615.

(142) Perdew, J. P.; Burke, K.; Ernzerhof, M. Generalized Gradient Approximation Made Simple. Phys. Rev. Lett. 1996, 77 (18), 3865-3868.

(143) Hartwigsen, C.; Goedecker, S.; Hutter, J. Relativistic Separable Dual-Space Gaussian Pseudopotentials from H to Rn. Phys. Rev. B, 1998, 58 (7), 3641-3662.

(144) Soler, J. M.; Artacho, E.; Gale, J. D.; Garcia, A.; Junquera, J.; Ordejon, P.; Sanchez-Portal, D. The SIESTA Method for Ab Initio Order-N Materials Simulation. J. Phys.: Condens. Matter, 2002, 14 (11), 2745-2779.

(145) Fernandez-Seivane, L.; Oliveira, M.; Sanvito, S.; Ferrer, J. On-site approximation for spin orbit coupling in linear combination of atomic orbitals density functional methods J. Phys.: Condens. Matter, 2006, 18 (34), 7999-8013. 